\title{
Too Many Men, Too-Short Lives: The Effect of the Male-Biased Sex Ratio on Mortality
}

\author{
by \\ Simon Chang ${ }^{*}$, Kamhon $\mathrm{Kan}^{\dagger}$, and Xiaobo Zhang ${ }^{\ddagger}$
}

\begin{abstract}
Using a natural experiment in Taiwan, this paper shows that, for men, exposure to male-biased sex ratios at a marriageable age is associated with a greater likelihood of death in later life. In the late 1940s, over half a million soldiers from mainland China retreated to Taiwan after a civil war and were initially subjected to a marriage ban. When the ban was lifted in 1959, the great influx of mostly male soldiers into the marriage market suddenly tipped the balance in favor of women. We have found that men subjected to this massive marriage market squeeze exhibited higher mortality rates at ages 50-64. We offer several possible explanations. Surprisingly, an elevated mortality rate, albeit of a much smaller magnitude, was also observed among the women of the relevant age groups. We show that this is likely driven by the widowhood effect—women’s mortality rate increased after their husbands’ deaths.
\end{abstract}

Keywords: Sex Ratio, Mortality, Marriage Market, Widowhood Effect

JEL Codes: I1, J1

\section{Acknowledgement:}

We greatly appreciate comments from seminar participants at University of Melbourne, University of Western Australia, Peking University and 2016 Asia Meeting of the Econometrics Societies. We also thank three anonymous referees for their constructive suggestions. The remaining errors are ours. Kamhon Kan gratefully acknowledges financial

\footnotetext{
* Simon Chang is a senior lecturer at the University of Western Australia, a research fellow at Institute of Labor Economics (IZA) and a fellow at Global Labor Organization (GLO).

${ }^{\dagger}$ Kamhon Kan is a research fellow at the Institute of Economics, Academia Sinica.

${ }^{\ddagger}$ Corresponding author: Xiaobo Zhang is a chair professor at Peking University and senior research fellow at the International Food Policy Research Institute (IFPRI). x.zhang@gsm.pku.edu.cn
} 
support by the Ministry of Science and Technology of Taiwan through grant 108-2410-H-001 -039 -MY3. Xiaobo Zhang gratefully acknowledge financial support from the National Natural Science Foundation of China [grant numbers 71874008, 71441008, 71873121, and 71950011]. 


\section{Introduction}

Marriage is an important decision in human life, and disturbances in the balance of the sex ratio (the ratio of men to women) in the marriage market can have lasting and far-reaching effects. An emerging body of literature has examined the economic and social consequences of male-biased sex ratios in a young cohort for savings (Wei and Zhang 2011a), entrepreneurship (Wei and Zhang 2011b; Chang and Zhang 2015), housing (Wei, Zhang, and Liu 2017), household financial decisions (Li et al. 2020), crime (Edlund et al. 2013; Cameron, Meng, and Zhang 2019), bargaining power (Francis 2011; Chang, Connelly, and Ma 2016), and cultural attitudes and social norms (Grosjean and Khattar 2019; Alix-Garcia et al. 2020; Baranov et al. 2021). But the effects on health remain relatively unknown. To fill the gap, this paper focuses on the long-term effects of the male-biased sex ratio on mortality.

In a marriage market with excess men, heterosexual men must compete harder to attract potential female partners. As implied in recent laboratory experiments, heightened mating competition likely results in higher stress for men (Bucket et al. 2017; Zhong et al. 2018). Since stress is a well-known risk factor for many health problems, such as high blood pressure, coronary heart disease, and cancer (Sterling and Eyer 1981; Price et al. 1994; Gilbert et al. 2009; Thoits 2010), it is plausible that an extremely competitive marriage market could have a deadly effect on health in later life.

Men who fail in the marriage market competition may remain bachelors for life. Many studies have shown that unmarried men tend to have a higher mortality risk than married men (see Wang et al. (2020) for a recent systematic review). ${ }^{4}$ Even for married men, the existence of a large number of bachelors poses an external threat to their marriages and thus reduces their

\footnotetext{
${ }^{4}$ Using the Health and Living Status of the Middle-Aged and Elderly Survey done in Taiwan in 1996, we estimated the Cox model for men and found that the mortality risk for the single and widowed men is, respectively, about $76 \%$ and $85 \%$ higher than for married men. The results are available upon request.
} 
intra-household bargaining power. Being in a disadvantageous position within the household, husbands have to work harder to provide for their families. This constitutes a source of constant stress (Angrist 2002; Chang, Connelly, and Ma 2016). Thus, even men who had succeeded in the marriage market and have a spouse continue to deal with stress after marriage.

However, there are challenges for identifying the effects of the sex-ratio imbalance on mortality. A major challenge is the endogeneity of sex-ratio imbalances. Large-scale sex-ratio imbalances can result from events that can directly affect adult mortality without necessarily operating through the sex ratio. For example, warfare and gender-specific advancements in medical technology could have a direct impact on gender-based differences in mortality while also distorting the sex ratio. It is subsequently difficult to separate the effect of the sex-ratio imbalance from the direct effect of warfare or technology.

This paper attempts to circumvent this challenge by using the sex imbalance created by the migration of soldiers from China to Taiwan after WWII and the removal of the marriage ban on these soldiers in the late 1950s. This event serves as a natural experiment point to identify causality. ${ }^{5}$ In the late 1940 s, about half a million of Chiang Kai-shek’s soldiers, mostly unmarried young men, retreated to Taiwan after a civil war against Mao Zedong's People’s Liberation Army (PLA) in mainland China. The local Taiwanese civilian population numbered only six million at the time. Upon their arrival in Taiwan, Chiang's soldiers were immediately deployed in every county throughout the island to defend against the PLA's attacks from the west, across the Taiwan Strait.

For a long time, to keep up their morale and their determination to recover the mainland, the soldiers were confined to military compounds and not allowed to marry. The marriage ban was ultimately lifted in 1959, injecting a large number of bachelors into the marriage market

\footnotetext{
${ }^{5}$ Some previous studies use distant historical events which generated sex-ratio imbalances for identification (e.g., Alix-Garcia et al. 2020 and Baranov et al. 2021), assuming that these events do not affect the outcomes of interest directly.
} 
in Taiwan. This large-scale natural experiment in Taiwan—with rather homogeneous cultural and institutional environments across counties_-resulted in both geographical and temporal variations in the sex ratios in the local marriage markets. The intensity of the marriage market competition differed across counties mainly due to variations in the military deployment in each county. A spike in the sex ratio (more men than women) intensified competition among the men but boosted the women's competitive advantage in the marriage market.

A few previous papers also used this natural experiment in Taiwan to examine various outcomes. Francis (2011) found that the elevated sex ratio increased the bride price relative to the dowry and increased the fraction of female children but decreased the total number of children in a family. Our paper differs from Francis's (2011) in two major ways. First, the outcome variable is different (our paper focuses on mortality). Second, the imputed effective sex ratio in Francis (2011) did not take the removal of the marriage ban in 1959 into account. The policy change was our main identification strategy, which is more precise sharper than that used by Francis. In addition, we have used more up-to-date statistics recently released by the Veteran Affairs Council in Taiwan, which enable us to better estimate the distribution of veterans across space and time.

Also, using the same natural experiment as in this current study, Chang and Zhang (2015) found that men exposed to high sex ratios were more likely to become entrepreneurs, while Chang, Connelly, and Ma (2016) examined how married couples spent their time and found that, with high sex ratios, husbands worked more and enjoyed less leisure time than wives. The resulting hard work and increased risks that men face in the marriage market competition are likely detrimental to their health, which is the focus of this paper.

This paper is the first to investigate the long-term impact of fierce marriage competition on adult mortality. We tracked the mortality of the affected cohort and other cohorts over the past six decades and found that young men subjected to this massive marriage market shock 
exhibited a higher death rate at ages 50-64. Surprisingly, the male-biased sex ratio also increased the death rate of women in later life, although to a much smaller extent. We show that this is likely due to the widowhood effect—women's mortality rate increased after their husbands' deaths.

Our findings also bring a new, though still gloomy, perspective to Sen’s (1992) query on missing women in many parts of Asian countries. Our findings imply that the "neglect of female health and nutrition” leading to excess female mortality (Sen 1992) actually has unintended dire consequences for men as well. That is, our findings predict an elevated likelihood of death in late adulthood for men born after the 1980s in China, India, and other Asian countries where sex ratios have become skewed (Sen 1992; Coale and Banister 1994; Das Gupta 2005; Bulte, Heerink, and Zhang 2011; Li, Yi, and Zhang 2011).

The rest of the paper is arranged as follows. The ensuing section, section 2, introduces the background of the marriage policy for soldiers in Taiwan and the construction of sex ratios, while section 3 discusses the datasets used in the analyses. Section 4 presents the empirical analyses of the effects of exposure to sex-ratio imbalances during marriageable age on mortality in later adulthood for men and women. Next, we discuss potential mechanisms in section 5, and section 6 provides a conclusion.

\section{Historical Background}

In China, the Chinese Nationalist Party (also known as the Kuomintang), led by Chiang Kai-shek, and the Chinese Communist Party (CCP), led by Mao Zedong, fought each other in a civil war between 1945 and 1949. With the defeat of the Kuomintang, there were waves of large-scale evacuations of soldiers and civil servants and migrations of civilians. There are no official statistics about these migrants. However, previous studies and evidence from different sources suggest similar estimates of the number of migrants from mainland 
China and the proportion of males among these migrants. About 1.2 million mainland Chinese came to Taiwan, with around half of them being soldiers and more than $80 \%$ of them being male. More specifically, Lin (2018) shows that, based on the population census of 1956, the total number of civilian migrants from mainland China between 1946 and 1952 amounted to 568,211. He also points out that most of the civilian mainland Chinese arriving in Taiwan after the civil war were either civil servants or dependents of the military personnel and the civil servants.

Recently the Veteran Affairs Council in Taiwan released statistics on veterans. ${ }^{6}$ In 1995, the earliest year for which data are available, there were 412,425 surviving veterans, most of whom were from mainland China. 198,918 had passed away. Assuming that $95 \%$ of the deceased veterans came from mainland China, the total number of soldiers who had retreated from to Taiwan amounts to 601,397, which is close to the ballpark figure of 600,000 given by Francis (2009). Among the veterans surviving in 1995, 98.4\% were men. If we add the inflow of servicemen and civilians together, the total number of migrants from mainland China reaches $1,169,608$. The ratio of men to women in the group was as high as 4.80 , which is consistent with Francis's estimate (2011) that men outnumbered women four to one among the mainland Chinese immigrants. In 1946, the population of Taiwan was only six million (Lin 2003). Using the population age structure in 1945 as a benchmark (Jiang, Mi, and Zhang 1996), we estimate that the marriage-age population (between ages 20 and 49) in Taiwan in 1946 was about 2.3 million (37.7\% of 6 million).

With the sudden influx of 1.2 million people from mainland China, including nearly one million young men, the sex ratio among the marriage-age group became highly skewed. Assuming that the sex ratio among the marriage-age Taiwanese had been balanced in 1946, by the late 1940s and early 1950s it is estimated to be as high as 157 men per 100 women.

\footnotetext{
${ }^{6}$ The data can be accessed at https://www.vac.gov.tw/cp-2009-2898-1.html.
} 
Upon arriving in Taiwan, Chiang's soldiers were immediately deployed in every county on the island to defend against the CCP's attacks. For a long time after their arrival, the soldiers were confined to their military bases and were not allowed to marry to ensure they remained vigilant and ready for warfare (Lin 2002). In 1952, the marriage ban was formally written into law as the Military Marriage Ordinance (MMO). The MMO forbade most active military personnel from marrying, except for military officers and technical sergeants. ${ }^{7}$ However, in August 1959, the ban was relaxed for most soldiers, except for male soldiers under 25 years old, female soldiers under 20 years old, and all soldiers who had served for fewer than three years. This relaxation made the MMO nonbinding for most immigrant soldiers, who by 1959 were either older than 25 or had served for over three years. This meant that they could finally get married, roughly 10 years after their arrival in Taiwan. It is worth noting that, even once married, the soldiers were not allowed to move away from military bases until they were discharged from active duty (Lin 2003). According to Peng (2004), massive discharges did not occur until 1965. Therefore, the peak of effective sex ratios does not overlap with the timing of the massive discharges. Before 1959, only about 77,000 soldiers were discharged, accounting for under $13 \%$ of the total military force (Lin 2003). About 40,000 of the discharged soldiers were assigned to work on major public projects and state farms, and about 30,000 injured or disabled soldiers were put into veteran nursing homes. Thus, the discharged veterans were few and largely isolated from the local private-sector jobs before 1959.

Even after discharge, most veterans still lived near their previous military bases. Panel A in Figure A1 demonstrates that, in 1956, Chinese mainlanders tended to cluster around

\footnotetext{
${ }^{7}$ Consequently, the impact of the influx of mainland migrants on Taiwan's local marriage market was largely mitigated by the MMO. The marriage rate for men in 1950 and 1958 was $60 \%$ and $61 \%$, while women's marriage rates were 62\% and 64\% respectively (The Household Registration Statistics of Taiwan in 1959). There is no evidence of rising marriage rates among men in anticipation of the eventual lifting of the marriage restriction on soldiers in August 1959.
} 
military bases in a map at the township level. For example, counties such as Taipei, Taoyuan, and Kaohsiung, which had more military bases than others, also had a greater presence of mainlanders (indicated by darker green). Panel B shows the distribution of mainlanders in 1956 as well as veterans, both living and deceased, across counties in 1996. It is apparent from the figure that the distribution of mainlanders closely resembles the distribution of veterans, with a correlation coefficient as high as 0.802 . All this indicates that the mobility of mainland migrants was limited even after the MMO was lifted. Given the limited mobility of the soldiers, with a sudden injection of about half a million bachelors into the marriage market after the lifting of the MMO, the effective local sex ratio for the cohort aged 25-40 immediately became skewed toward men in areas with military bases and state farms. ${ }^{8}$

Most of the mainland Chinese soldiers were in their 20s when they arrived in Taiwan in 1949. By the time the marriage ban was lifted in 1959, most were in their 30s. The two largest age groups among the mainland migrants represented in the Taiwan Population and Housing Census in 1956 are the 30-34 and 35-39 cohorts, each accounting for about 20\% of the total mainland migrant population in Taiwan (Lin, 2002). Therefore, our paper focuses on ages 30 and 35 in the main analysis. We used the sex ratios at the county level to measure the intensity of the local marriage market competition for the respective ages. The sex ratio for age 30 for any county is defined as the ratio of men to women in the age range 25-34 who resided in the county in the year they turned 30. Similarly, the sex ratio for age 35 is defined as the ratio of men to women in the age range 30-39 who resided in the county in the year they turned 35. Our choice of age range in calculating the sex ratios is based on the assumption that a man competes in the marriage market with others from the same five-year

\footnotetext{
${ }^{8}$ Ong et al. (2020) show that there is a "leftover women" phenomenon in mainland China, despite the increasing number of men in the marriage market in the past several decades, due to elite women's inclination to marry richer men. If this holds true for Taiwan, the existence of "leftover women” would further reduce the number of available women in the marriage market, creating even more intense competitive pressures for men, particularly those with a lower social status.
} 
age range. As a robustness check, we also extended the age range to 15-49 and found similar results.

The Taiwanese government tracks residency through a household registration system, and every citizen is required to be registered with a local branch of the Department of Household Registration of the Ministry of the Interior immediately after birth or becoming a resident. The registration records contain detailed information regarding date of birth, relocation history, marriage status and spouse information, educational attainment, etc. for each household member. However, for national security reasons, active military personnel, including soldiers from mainland China, were excluded from this registration system until 1969. Since some of our study cohorts reached age 30 before 1969, we had to impute the county sex ratios to include those soldiers, which accounted for about $40 \%$ of the observations. We followed the method proposed by Chang (2013), using the population data administered by the Department of Household Registration under the Ministry of the Interior. Appendix 1 provides a brief description of the imputation method.

Figure 1 shows the sex ratios at ages 30 and 35 by birth cohort. The declining trends show that the older cohorts experienced higher imbalances in sex ratios than the younger cohorts. For instance, there were as many as 126 men for every 100 women (sex ratio 1.26) in the age range 30-39 when the 1931 cohort reached age 35 . However, the ratio dropped to only 105 men for every 100 women for the 1939 cohort. Those mainland Chinese soldiers were mostly born in the late 1920s and early 1930s. When the MMO was abolished in 1959, many of these solders were in their 30s. This explains why the sex ratios at age 30 and 35 were the highest for the 1931 birth cohort, the oldest cohort available in our sample, as shown in Figure 1, as they were 28 years old in 1959. Given that the average marriage age for men at the time was about 27 (Chen 2012), their marriage prospects would have been dim in the face of the sudden influx of military servicemen aged 30-35 in the marriage market. The 
effect may have persisted until they were in their 30s. Thus, the sex ratio at age 30 or 35 remained relevant for them.

Given the shortage of women in their age group, it is not surprising that mainland migrant men married late. According to our estimate, based on the Health and Living Status of the Middle-Aged and Elderly Survey in Taiwan from 1996 and 2003, mainland migrant men got married at age 33, seven years later than their Taiwanese counterparts. As for women, mainland Chinese women got married at age 25, three years later than their Taiwanese counterparts.

The sex ratios also vary greatly across counties. Figure 2 shows the average county sex ratio (averaged across birth cohorts) at age 30 in panel $\mathrm{A}$ and at age 35 in panel $\mathrm{B}$. The sex ratio at age 30 was 1.19 in Taipei City, in comparison with 1.09 in Tainan City. Overall, the large variation in sex ratios at ages 30 and 35 caused by the MMO across cohorts and counties provides a good opportunity to examine the impact of exposure to sex ratio disturbance in people's 30s on their mortality a few decades later.

\section{Data}

We studied the birth cohorts born from 1931 to 1950, who reached age 30 between 1961 and 1980. To facilitate our empirical analysis, we used several data sources described in detail below.

\section{Mortality Data}

We imputed age-specific mortality rates by gender and county by using death counts from the national death registry data between 1981 and 2014 and population at risk from the 1980 Population and Housing Census in Taiwan. The national death registry is maintained by the Ministry of Health and Welfare. It records a deceased individual's sex, year of birth and death, and county of birth or, for migrants, county of residence (as indicated by the first digit 
of the national ID number), all of which is reported by the hospital where the individual was last treated or by the Prosecutors Office if the individual was dead on arrival. The 1980 Population and Housing Census was administered by the Ministry of the Interior and recorded sex, year of birth, and county of residence for all residents of Taiwan at the end of 1980.

Under the two assumptions stated below, these two data sources allow us to impute mortality rates at ages $50-54,55-59,60-64$, and $50-64$ by sex and county of birth for all birth cohorts who were born between 1931 and 1950 and were still alive in $1980 .{ }^{9}$ For instance, the mortality rate at ages 50-54 for men of the 1931 birth cohort in county $c$ is defined as the number of men from this birth cohort who were born in county $c$ and died between 1981 and 1985 divided by the total number of men from this birth cohort who were still alive in 1980 in county $c$.

The imputation is made under two assumptions: first, that an individual's county of residence in 1980 is the same as his or her county of birth; second, that there is no migration during this period. Any violation of these two assumptions could inject measurement errors into the mortality rate, which is our key outcome variable. We assume that the potential measurement errors in the mortality rate are orthogonal to the covariates included on the right-hand side of the regression equation. It is unlikely that the right-hand-side variables, especially the imputed sex ratios, are correlated with the measurement errors in the imputed mortality rate.

\footnotetext{
${ }^{9}$ We chose these cohorts for the following reasons. First, our mortality data stretch from 1981 to 2014. Second, since our mortality rate is age specific, we needed to observe mortality at the same ages for all birth cohorts. Third, we wanted to examine mortality rate in as large an age range as possible, starting from age 50 . This meant that we could only look at cohorts born in 1931-1950 and examine their mortality rates at ages 50-64. The youngest cohort, born in 1950, was 64 in 2014. Of course, many of them were still alive by 2014. Therefore, we narrowed the age group to 50-64 in our main analysis.
} 
Since the sex ratio is also an imputed variable, there is still a possibility that the measurement errors in the imputed mortality rate and the imputed sex-ratio are correlated. To remedy this concern, in our estimation we use an instrumental variable approach. To construct our instrumental variable, we used the number of mainland Chinese men in each county interacted with the world average gender differential in mortality rate. ${ }^{10} \mathrm{We}$ calculated the number of mainland migrant men in each county using the Population and Housing Census of 1956. We drew the worldwide mortality data from the Abridged Life Table for Males and Females in the World Population Prospects 2019, which is published by the Population Division, Department of Economic and Social Affairs, United Nations. ${ }^{11}$ The validity of this instrument will be explained in Section 4.

Figure 3 plots the trend of mortality rate at ages 50-64 by sex for cohorts born between 1931 and 1950. It is apparent that women’s mortality rate has steadily declined over birth cohorts. By comparison, men’s mortality rate barely changes for the cohorts born between 1931 and 1944. Men born in 1931-1944 were aged 15-28 in 1959 when the marriage ban was removed. Therefore, they faced intense mating competition from a larger number of older male veterans. The elevated marriage market competition likely took a toll on men's health, offsetting the positive effect of improvement in standard of living and medical technologies on life expectancy over time, which might have contributed to the decline in women's mortality rate over birth cohorts. As a result, the gender gap in mortality rate widens during this period. The decline in mortality becomes noticeable only for cohorts

\footnotetext{
${ }^{10}$ The main reason why we use this interaction term instead of using them as two separate instruments is that each of the two variables only varies in one dimension, while the sex ratio differs in both spatial and temporal dimensions. The sex ratio varies across counties and birth cohorts. The number of mainland Chinese men in 1956 only varies across counties, while the gender mortality differential only changes over birth cohorts. Since we already control for county- and birth-cohort-fixed effects, we cannot use the number of mainland Chinese men or the gender mortality differential as an instrument.

${ }^{11}$ Taiwan's Abridged Life Tables are available at https://www.moi.gov.tw/stat/node.aspx?cate_sn=\&belong_sn=5992\&sn=6028. The World Population Prospects 2019 data are available at https://population.un.org/wpp/.
} 
born in 1945 and after. The 1945 birth cohort turned the average marriage age of 27 in 1972, by which time the sex ratio had largely returned to normal.

\section{Other Data Sources}

The Health and Living Status of the Middle-Aged and Elderly Survey (HLSMES) in Taiwan is a longitudinal survey conducted by the Health Promotion Administration under the Ministry of Health and Welfare. The survey collected detailed information, including demographics and various health outcomes. This allows us to examine a variety of health outcomes, e.g., chronic conditions and depression, for the cohorts born between 1929 and 1953. We combined two nationally representative samples separately drawn in 1996 and 2003 to form our analysis sample of 4,061 individuals. Their health outcomes were evaluated in 1996 and 2003 respectively.

Some male-intensive industries, such as construction and mining, are inherently more dangerous. They tend to have higher workplace injuries and death rates than female-intensive industries, such as the garment industry (Tan, Wei, and Zhang, 2021) and are more likely to be located in areas with a high sex ratio. Thus, there is a possibility that the observed effect of skewed sex ratios on adult mortality is due to the nature of risk jobs inherent in the maleintensive industries. To address this concern, we include two variables-industry male ratio and risky job share at the county level—as regressors in the regression model for mortality rate. Industry male ratio is the weighted average of male-to-female ratio of a county's industries. It is computed as follows:

$$
M_{i}=\sum_{j} E_{i j} * M_{j},
$$

where $E_{i j}$ is county i's number of employments in industry $j$ and $M_{j}$ is industry $j$ 's male-tofemale ratio, which is computed using the May file of the 1969-1970 May Current Population Survey data in the United States. The county-level employment by industry $E_{i j}$ is obtained from the 1954, 1966, and 1976 Reports of Industry and Service Census. The reason 
why we us the Current Population Survey in the United States instead of Taiwan's data to compute $M_{j}$ is that Taiwan's male-to-female ratio at the industry level may be affected by its imbalanced sex-ratio such that it is endogenous in the mortality regression, while the sexratio in the United States was pretty much balanced during 1969-1970. A county's industry male ratio may affect internal migration: a county with a high industry male ratio indicates more job opportunities for male workers and hence attracts male migrants. Counties with a high sex ratio may also attract male-intensive industries. The industry male ratio in the United States largely reflects industry-specific demand for male workers relative to female workers.

Risky job share is defined as the proportion of county-level employments in the following industries: forestry and hunting, mining, quarrying, oil and gas extraction, construction, transportation, and warehousing, which have high occupational injury rates according to the BLS statistics in the United States. ${ }^{12}$ Using data from the U.S. to define risky industries avoids the possibility that Taiwan's sex-imbalance affected the sorting of individuals into particular industries and industry-specific injury rate. Tan, Wei, and Zhang (2020) have used a similar approach to define risk jobs when examining the impact of the sex-ratio imbalance on workplace safety. The number of employessee in these risky industries and total employment at the county level are also obtained from the 1954, 1966, and 1976 Reports of Industry and Service Census in Taiwan. The risky job share is likely correlated with a county's mortality rate. It may be correlated with a county's sex-ratio given that certain risky jobs—e.g., those in construction-are male-dominated.

In the end, we have only three time points—1954, 1966, and 1976 - for these two variables. Because we need to evaluate these two variables when each of our study cohorts

\footnotetext{
${ }^{12}$ See https://www.bls.gov/iif/oshwc/cfoi/cfoi_rates_1992.pdf.
} 
(born 1931-1950) reached age 30, we linearly interpolate and extrapolate for all other years during 1961-1980 based on data for these three years.

\section{Empirical Analysis}

\section{Ordinary Least Squares Regressions}

Mortality rate in middle age may be driven by cohort-specific or county-specific unobserved factors. We ran a multivariate regression, as shown below, to control for countyand birth-cohort-fixed effects.

$M_{c b a}^{g}=\beta^{g} S_{c b}+\alpha^{g} \log$ Male $_{c b}+\gamma^{g} \boldsymbol{X}_{c b}+\gamma_{b}+\delta_{c}+\varepsilon_{c b a}^{g}$,

where $M_{c b a}^{g}$ is the county-level mortality rate for males $(g=m)$ or females $(g=f)$ at age $a$ for birth cohort $b$ in county $c$; $S_{c b}$ is the sex ratio in county $c$ when cohort $b$ was 30 or 35 years old; ${\log M a l e_{c b a}}_{\text {is }}$ the natural log of the number of prime-age men (20-64 years old) in county $c$ when cohort $b$ was at age $a ; \boldsymbol{X}_{c b a}$ is a vector of local county characteristics (industry male ratio and risky job share); $\gamma_{b}$ is the cohort-fixed effect; $\delta_{c}$ is the county-fixed effect; and $\varepsilon_{c b a}^{g}$ is an error term. We used robust standard errors clustered at the county level for statistical inferences.

In addition to cohort- and county-fixed effects, we also controlled for the number of prime-age men in logarithmic form in order to capture the effect of the influx of male workers into the labor market. With the number of women in a county being more or less stable, simply adding more prime-age men could intensify the competition in the labor market for men. The heightened competition in the labor market could take a toll on mortality for men in later life, even though it is not driven by marriage competition. Furthermore, we also control for the share of risky jobs and industry male-to-female ratio that may correlate with both the sex ratio and subsequent mortality. 
We visualized all point estimates with the 95\% confidence interval in Figures 4-9. Unless otherwise noted, we use circles and crosses to denote estimates for men and women respectively. Tables of all estimation results are provided in the appendix.

Figure 4 shows the ordinary least squares (OLS) estimates of the sex-ratio effect on age-specific mortality rates. Throughout all age ranges, both men’s and women’s mortality rates appear to be positively associated with sex ratios. Nonetheless, the effects associated with men are generally three times greater than those associated with women. For example, at age 50-64 (panel D), if the sex ratios increase by one standard deviation (about 0.1 or 10 extra men per 100 women), men’s mortality rate increases by about $1.5 \%$. In comparison, for the same increase in sex ratios, women's mortality rate during ages 50-64 would increase by only about $0.5 \%$.

Potential Biases in the OLS

The OLS estimates may be biased for several reasons. First, the sex-ratio variable is subject to measurement errors. Since the ratios are imputed for some years, measurement errors may arise from this imputation. The sex ratio at the county level is computed based on people's current county of residence, which may have changed after marriage. Thus, there could be potential errors in matching individuals with the actual sex ratios relevant to them. Measurement errors may also arise from inter-county migration: mainland migrants might have different migration patterns from the native Taiwanese throughout their lives, seeking either a spouse or job opportunities, since they have fewer family members tying them down geospatially. However, as shown in Figure A1, most veterans did not move far from their military bases after discharge. Since the sex-ratio variable is mainly determined by the presence of male veterans, their low mobility tendency implies that the measurement errors resulting from their migration are likely small. 
Second, high sex ratios signal a heavy presence of male mainland migrants, whose health might have been compromised by their earlier civil war experiences back in mainland China. In this case, the sex-ratio variable measures not only the effect of marriage market competition but also the scarring effect of war, because counties with a higher sex ratio would also have had more veterans, whose health would be worse than that of the native Taiwanese. As a result, the OLS estimates of sex ratios would overestimate the effect of marriage market competition by capturing the war-scarring effect. However, these concerns can be largely dismissed. The mainland Chinese migrants were on average better educated than their local counterparts (see Figure A2 in the Appendix). Under Chiang Kai-shek’s reign, the mainland Chinese occupied most of the better-paid public sector posts, received more government support and subsidies for employment, were entitled to better medical care, and were more educated than native Taiwanese (Hermalin et al. 2009; Cheng and Swee 2019). Hermalin et al. (2009) found that these favorable treatments had offset the harmful war experiences of the male mainland migrants. A recent study by Chang and Wu (2020) shows that male veterans actually enjoyed a lower mortality rate than local men. Based on the administrative database maintained by the Veteran Affairs Commission, Chang and Wu found that, as of 2017, the average survival time for all the living male veterans in Taiwan in 1996 was 2.16 years longer than that of native Taiwanese men. The baseline dataset from 1996 includes 475,827 veterans over the age of 40, 98.2\% of whom were male. Given that 95\% of veterans came from mainland China, this finding means that male veterans who had migrated from mainland China likely lived longer than native Taiwanese men. Thus, the observed negative effect of sex ratios on mortality is unlikely to be driven by the scarring effect of war experiences.

Third, mortality selection exists because we only looked at mortality at ages 50-64 for birth cohorts born in 1931-1950 due to data constraints. We could not include those who had 
died before their 50th birthday in the analysis sample. However, this should not cause any bias, because we define our estimates as the effect on age-specific mortality conditional on having lived to at least age 49. If there exists a strong mortality sections selection before 50 for men in high-sex ratio regions, then our sample would consist of men with better health, indicating that our estimates would be biased toward zero, making it more difficult to find a negative impact on health. Yet, we still found a negative effect.

To address the potential bias in OLS, we adopted the instrumental variable approach. We discuss our instrumental variables and their validity below.

\section{Instrumental Variables}

To construct our instrumental variable, we interacted two variables that are correlated with the county sex ratios but are arguably unrelated to the measurement errors: the number of mainland Chinese men (excluding soldiers) who had retreated to Taiwan and worldwide gender difference in mortality at age 20. We used the actual number of mainland Chinese men in each county from the 1956 Population and Housing Census, which was the first census conducted after Chiang Kai-shek’s government relocated to Taiwan and also has the earliest data available. For the sake of confidentiality, the male mainland migrants in this census did not include those soldiers from mainland China. The presence of the male mainland migrants in each county in 1956 is partially correlated with the county sex ratios in the 1960s, 1970s, and 1980s after the marriage ban was lifted in 1959. Yet, the number of mainland Chinese men in 1956 only varied across counties. Many discharged veterans and family members of married military officers from mainland China lived near their military bases. As a result, the number of mainland men (excluding soldiers) observed in the 1956 population census, which is supposedly accurately counted, is spatially correlated with the number of actively serving mainland soldiers. 
The second variable we used is the worldwide gender differential in mortality rate when the cohort reached age 20 , which is unlikely to be determined by the unobserved factors in Taiwan. Note that this variable only varies with birth cohort by construction. The worldwide gender differential in mortality at age 20 reflects the state of medical technologies and men's health relative to women's health (as indicated by mortality risk) when each cohort reached age 20. The gender differential in mortality rate at age 20 in Taiwan likely resembled the worldwide trend, even though the level may have been different. The worldwide gender differential in mortality at age 20 therefore, to some extent, shapes the sex ratio at age 30 or 35 faced by our studied cohorts in every county. The interaction between time-varying worldwide gender differential in mortality at age 20 and the time-invariant spatial distribution of mainland Chinese men provides a good proxy for sex ratios at ages 30 and 35 across counties in Taiwan.

The instrument variable meets the random assignment requirement. First, the distribution of Mainland Chinese men in 1956 was mostly determined by the locations of Chiang Kai-shek’s government agencies and military bases since his followers consisted of civil servants, military personnel, and their dependents (Lin 2002). The spatial distribution of the mainland Chinese persisted over time and was highly correlated with the initial distribution of military bases (see Figure A1). The spatial distribution in 1956 also predates all the sex ratios used in our analysis. Second, the worldwide gender differential in mortality is unlikely to be determined by any local factors in Taiwan, given the small population and economic irrelevancy of Taiwan in the 1950s.

The two variables also meet the condition of exclusion restriction. Given that mainland Chinese men enjoyed a mortality advantage, the presence of a large number of male mainland migrants in 1956 would itself have mechanically lowered the average mortality rate, making it more difficult for us to find a negative impact. The male mainland migrants, 
however, could have had a direct impact through the channel of the labor market. Once veterans were discharged, they competed for limited jobs. The elevated job market competition itself could result in higher mortality later in life, in addition to the consequences of marriage market competition. However, massive discharges did not happen until 1965, six years after the lifting of the marriage ban. Consequently, the peak of effective sex ratios does not overlap with the timing of the massive discharges. Nonetheless, to address this concern, we have included in all regressions the number of prime-age men in logarithm so as to control for the labor-market effect.

The worldwide gender differential in mortality at age 20 mainly reflects the worldwide trend in men's and women's mortality at age 20, which varies across cohorts and may have been correlated with men's and women's later mortality in Taiwan if we had not controlled for the birth-cohort-fixed effect. Therefore, we have controlled for the birthcohort-fixed effect in regressions.

Two-Stage Least Squares Results and Robustness Checks

With the above instrumental variables, we conducted two-stage least squares (2SLS) estimations. Table A2 in the appendix displays the results of the first-stage regressions for sex ratios using two different instrumental variables: the interaction of the log of the number of male mainland migrants with the worldwide gender differential in mortality rate at age 20 when the cohort reached age 20. The instrumental variable is correlated with sex ratios at ages 30 and 35 and is statistically significant at the $1 \%$ level. The Kleibergen-Paap F statistic is above 37 , which exceeds the critical value of 16.38 for a maximum bias of $10 \%$ (see Stock and Yogo 2005), indicating that the instrument is strong enough for identification.

Figure 5 presents the 2SLS estimates using the interaction of the log number of mainland Chinese men with the worldwide gender difference in mortality rate at age 20 when each birth cohort reached age 20. The 2SLS estimates show patterns similar to those observed 
in Figure 4 but are generally 1.5 to 2 times greater than the OLS estimates. For example, an increase of one standard deviation in the sex ratios would lead to an increase in men's mortality rate at ages $50-64$ by about $3 \%$. For women, the effect is less than $1 \% .^{13}$

So far, we had defined sex ratios using an age range of five years above and below the age of the cohort members. As another robustness check, we extended the age range to 1549, which should cover most of the active participants in the marriage market. The results of both the OLS (panels A-D) and 2SLS (panels E-H) are shown in Figure 6. Again, the patterns observed are consistent with previous results.

We also provide the reduced form estimates-i.e., the regressions of mortality on the instrumental variable, the interaction between the number of mainland men, and the worldwide gender difference in mortality when each cohort reached age 20, with and without local characteristics - in Figure A3 in the appendix. Because our data of mainland Chinese men is a snapshot of 1956, we cannot directly run a reduced form regression of cohortspecific mortality on the number of mainland Chinese men. Overall, the results show similar positive effects on mortality rates, with the effects being larger for men than women.

\section{Mechanisms}

\section{Other Health Outcomes}

Although we have been examining the effect of the sex ratio on mortality only, it is natural to suspect that it may also affect other health outcomes. We investigated a variety of chronic conditions using data from the Health and Living Status of the Middle-Aged and Elderly Survey in Taiwan. The sample consisted of individuals born between 1929 and 1953,

\footnotetext{
${ }^{13}$ In our data, average mortality at ages 50-64 (average across cohorts and counties) is 0.17 for men and 0.09 for women. Correspondingly, our 2SLS estimates of the mortality effect are 0.00406 for men and 0.0022 for women for every additional man per 100 women in the sex ratio at age 30 . This translates to about $2.4 \%$ of the average mortality for both men and women. Our 2SLS estimates of the mortality effect are 0.00443 for men and 0.00233 for women for every additional man per 100 women in the sex ratio at age 35 . This translates to about $2.6 \%$ of the average mortality for men and women.
} 
and we observed their health outcomes in 1996 and 2003. These outcomes include Center for Epidemiologic Studies Depression Scale (CES-D) scores, cancers, heart diseases, high blood pressure, stroke, and diabetes. The CES-D ranges from 0 to 30, with a higher value indicating more severe depression. All other chronic conditions are dummy variables indicating whether a person self-reported the condition in question.

Figures 7 and 8 show, respectively, the OLS and 2SLS estimates of the sex ratio's impact on these chronic conditions. As shown in Figure 7, the OLS estimates do not reveal any clear effect of the sex ratio on these outcomes. However, the 2SLS estimates in Figure 8 show that, after having faced higher sex ratios in their 30s, men do have a higher chance of developing cancers and high blood pressure later in life, whereas none of the estimates for women are statistically significant. Since cancers and high blood pressure have been leading causes of death in Taiwan, the findings are consistent with the gender difference in mortality outcomes we observed in the previous section. ${ }^{14}$

Widowhood Effect

The positive sex-ratio effect on women's mortality that our results suggest seems puzzling. Women who experienced the removal of the MMO were more likely to marry, and they supposedly had greater bargaining power within the household when considering the significant number of bachelors in the marriage market. Theoretically, the skewed sex ratio in the 30s in favor of women should have been good for their health and longevity; yet, we have observed a negative effect on women's mortality rate. We suspect that the widowhood effect is at play; that is, a woman's probability of dying increases with the death of her spouse. In other words, sex ratio has an indirect effect on women's mortality, operating through the negative effect on the health of their spouses. To test this, we added the mortality rate of

\footnotetext{
${ }^{14}$ According to the Ministry of Health and Welfare in Taiwan, malignant neoplasms and hypertensive diseases have been leading causes of death in Taiwan since the 1980s (see data available at https://dep.mohw.gov.tw/DOS/lp-1819-113-xCat-1.html).
} 
older men as a regressor into the regressions for female mortality. For instance, for women’s mortality rate at ages 50-54 and 55-59, we controlled for men's mortality at ages 55-59 and 60-64 respectively. For men's regressions, we added the mortality rate of women belonging to a younger birth cohort, considering that men tended to marry younger women in this context.

The mortality rate as a regressor is clearly endogenous and thus requires another instrumental variable to account for that. We used the gender difference in mortality in both Taiwan and the world and separately interacted them with the log number of male mainland migrants to form two instrumental variables. ${ }^{15}$ The OLS and 2SLS results are shown in Figure 9. Note the different symbols used to denote point estimates: in panels A and B, we use circles and crosses to denote women's sex-ratio effect on mortality at ages 50-54 and 5559 respectively; in panels $\mathrm{C}$ and $\mathrm{D}$, we use squares and triangles to denote men's sex-ratio effect on mortality at ages 55-59 and 60-64 respectively.

As shown in panel B, the 2SLS estimates of the sex-ratio effect for women turn negative, suggesting that sex ratios actually lower women's mortality once we control for men's mortality for the adjacent older age category. In stark contrast, controlling for younger women's mortality does not dilute the sex-ratio effect for men.

\section{Conclusion}

This paper examines the long-term effect of the male-biased sex ratio on mortality, using the removal of the marriage ban on soldiers in Taiwan in 1959 as a natural experiment. We have found that men exposed to the sudden elevation in marriage competition in young

\footnotetext{
${ }^{15}$ We note that Taiwan's gender difference in mortality may be subject to the same measurement error as the dependent variable, rendering the results biased.
} 
adulthood experienced a rise in mortality a few decades later. Interestingly, higher sex ratios also take a toll on women's mortality, likely due to the widowhood effect.

High sex ratios have persisted in some Asian countries, including China and India, for a few decades (Das Gupta 2005). However, the long-term hidden health costs of sex-ratio imbalances have not been well recognized. For the generations born to skewed sex ratios over the past several decades, the future mortality and health costs loom large. 


\section{REFERENCES}

Alix-Garcia, Jennifer, Laura Schechter, Felipe Valencia Caicedo, and S. Jessica Zhu. 2020. “Country of Women? Repercussions of the Triple Alliance War in Paraguay.” CEPR Discussion Paper No. DP1475.

Angrist, J. 2002. “How Do Sex Ratios Affect Marriage and Labor Markets? Evidence from America’s Second Generation.” Quarterly Journal of Economics 117, no. 3: 9971038.

Barclay, George W. 1954. Colonial Development and Population in Taiwan. Princeton, NJ: Princeton University Press.

Barclay, K. J. 2013. “Sex Ratios at Sexual Maturity and Longevity: Evidence from Swedish Register Data.” Demographic Research 29: 837-864.

Baranov, Victoria, Ralph De Haas, and Pauline A. Grosjean. 2021. "Men. Roots and Consequences of Masculinity Norms.” UNSW Business School Research Paper.

Berge, Lars Ivar Oppedal, Kjetil Bjorvatn, Armando Jose Garcia Pires, and Bertil Tungodden. 2015. “Competitive in the Lab, Successful in the Field?” Journal of Economic Behavior \& Organization 118: 303-317.

Buckert, M., C. Schwieren, B. M. Kudielka, and C. J. Fiebach. 2017. "How Stressful are Economic Competitions in the Lab? An Investigation with Physiological Measures.” Journal of Economic Psychology 62: 231-245.

Bulte, E., N. Heerink, and X. Zhang. 2011. “China’s One-Child Policy and 'the Mystery of Missing Women’: Ethnic Minorities and Male-Biased Sex Ratios.” Oxford Bulletin of Economics and Statistics 73, no. 1: 21-39.

Buss, D. M. 1989. “Sex Differences in Human Mate Preferences: Evolutionary Hypothesis Tested in 37 Cultures.” Behavioral and Brain Sciences 12: 1-14. 
Cameron, L., X. Meng, and D. Zhang. 2019. “China’s Sex Ratio and Crime: Behavioural Change or Financial Necessity?” Economic Journal 129, no. 618: 790-820.

Chang, Chih-chiang and Tung-lin Wu. 2020. “A Comparison of the Longevity between Veterans and Native Taiwanese.” Chu Chi Yueh Kan 770: 24-28.

Chang, S. 2013. “Civil War, Marriage Ban and Sex Ratio.” Asian Population Studies 9: 101118.

Chang, S., R. Connley, and P. Ma. 2016. “What Will You Do If I Say 'I do'?: The Effect of the Sex Ratio on Time Use within Taiwanese Married Couples.” Population Research and Policy Review 35, no. 4: 471-500.

Chang, S., and X. Zhang. 2015. “Mating Competition and Entrepreneurship.” Journal of Economic Behavior \& Organization 116: 292-309.

Chen, Kuan-Jeng and Tien-Fong Yeh. 1982. "Changes of Age Composition in Taiwan, 19051979.” National Taiwan University Journal of Population Studies 6: 99-114.

Chiappori, P.-A., S. Oreffice, and C. Quintana-Domeque. 2012. "Fatter Attraction: Anthropometric and Socioeconomic Matching on the Marriage Market.” Journal of Political Economy 120: 659-695.

Coale, A. and J. Banister, J. 1994. "Five Decades of Missing Females in China.” Demography 31: 459-479.

Das Gupta, M. 2005. “Explaining Asia’s Missing Women: A New Look at the Data.” Population and Development Review 31: 529-535.

Edlund, L., H. Li, J. Yi, and J. Zhang. 2013. "Sex Ratios and Crime: Evidence from China.” Review of Economics and Statistics 95, no. 5: 1520-1534.

Francis, A. 2011. "Sex Ratios and the Red Dragon: Using the Chinese Communist Revolution to Export the Effect of the Sex Ratio on Women and Children in Taiwan.” Journal of Population Economics 24: 813-837. 
Gilbert, Paul, Kirsten McEwan, Rebecca Bellew, Alison Mills, and Corinne Gale. 2009. “The Dark Side of Competition: How Competitive Behavior and Striving to Avoid Inferiority Are Linked to Depression, Anxiety, Stress and Self-Harm.” Psychology and Psychotherapy: Theory, Research and Practice 82: 123-136.

Grosjean, Pauline and Rose Khattar. 2019. “It’s Raining Men! Hallelujah? The Long-Run Consequences of Male-Biased Sex Ratios.” The Review of Economic Studies 86, no. 2: 723-754.

Ho, Sam P. S. 1978. Economic Development of Taiwan: 1860-1970. New Haven, CN: Yale University Press.

Hu, Y. and N. Goldman. 1990. “Mortality Differences by Marital Status: An International Comparison.” Demography 27, no. 2: 233-250.

Jacoby, Neil H. 1967. U.S. Aid to Taiwan: A Study of Foreign Aid, Self-Help, and Development. New York: F. A. Praeger.

Jin, L., F. Elwert, J. Freese, and N. A. Christakis. 2010. "Preliminary Evidence Regarding the Hypothesis that the Sex Ratio at Sexual Maturity May Affect Longevity in Men.” Demography 47, no. 3: 579-586.

Li, H., J. Yi, and J. Zhang. 2011. "Estimating the Effect of the One-Child Policy on Sex Ratio Imbalance in China: Identification Based on the Difference-in-Differences.” Demography 48, no. 4: 1535-1557.

Li, W., C. Song, S. Xu, and Yi Ji. Forthcoming. “High Sex Ratios and Household Portfolio Choice in China.” Journal of Human Resources.

Lin, M.-J., J.-T. Liu, and N. Qian. 2014. “More Missing Women, Fewer Dying Girls: The Impact of Sex Selective Abortion on Sex at Birth and Relative Female Mortality in Taiwan.” Journal of the European Economic Association 12, no. 4: 899-926. 
Lin, Sheng-Wei. 2002. “The Transition of Demographic Sexual Structure in Taiwan: 19052000.” National Chengchi University Journal of Sociology 33: 91-131.

Lin, Tung-Fa. 2018. “The Ins and Outs of Taiwan Population from the End of War to the 1950s.” Newsletter of Taiwan Studies 103: 4-7 (In Chinese).

Liu, Ke-Chih. 1986. Population Growth and Economic Development in Taiwan. Taipei, Taiwan: Linking Books.

Manzoli, L., P. Villari, G. M. Pirone, and A. Bocccia. 2007. "Marital Status and Mortality in the Elderly: A Systematic Review and Meta-Analysis.” Social Science and Medicine 64: 77-94.

Ong, D., Y. A. Yang, and J. Zhang. 2020. "Hard to Get: The Scarcity of Women and the Competition for High-Income Men in Urban China.” Journal of Development Economics 144: 1024334.

Peng, Ching-Peng. 2004. "Veteran Affairs Council and Prospect-the Establishment and Development of the Veterans Assistance System.” Paper presented at the Fiftieth Anniversary of the Veteran Affairs Council—Retrospect and Prospect Workshop. Taipei, Taiwan, October 15, 2004.

https://www.ea.sinica.edu.tw/file/Image/veteran.pdf

Price, John, Leon Sloman, Russell Gardner Jr., Paul Gilbert, and Peter Rohde. 1994. “The Social Competition Hypothesis of Depression.” British Journal of Psychiatry 164: 309-15.

Sen, A. 1992. “Missing Women.” British Medical Journal 304, no. 6827: 587-588.

Sterling, P. and J. Eyer. 1981. “Biological Basis of Stress-Related Mortality.” Social Science and Medicine 15: 3-42. 
Stock J, Yogo M. 2005. “Testing for Weak Instruments in Linear IV Regression.” In Andrews, DWK. Identification and Inference for Econometric Models. New York: Cambridge University Press. pp. 80-108.

Tan, Zhibo, S.-J. Wei, and X. Zhang. 2021. “Deadly Discrimination: Implications of 'Missing Girls’ for Workplace Safety.” Journal of Development Economics, 152: 102678.

Thoits, P. A. 2010. “Stress and Health Major Findings and Policy Implications.” Journal of Health and Social Behavior 51, suppl. 1: S41-S53.

Wang, Y., Y. Jiao, J. Nie, A. O’Neil, W. Huang, L. Zhang, J. Han, et al. 2020. “Sex Differences in the Association Between Marital Status and the Risk of Cardiovascular, Cancer, and All-Cause Mortality: A Systematic Review and MetaAnalysis of 7,881,040 Individuals.” Global Health Research and Policy 5:4. https://doi.org/10.1186/s41256-020-00133-8.

Wei, S.-J. and X. Zhang. 2011a. “The Competitive Saving Motive: Evidence from Rising Sex Ratios and Savings Rates in China.” Journal of Political Economy 119, no. 3: 511564.

Wei, S.-J., and X. Zhang. 2011b. “Sex Ratios, Entrepreneurship, and Economic Growth in the People’s Republic of China.” NBER Working Paper 16800. Cambridge, MA: National Bureau of Economic Research.

Wei, S.-J., X. Zhang, and Y. Liu. 2017. "Home Ownership as Status Competition: Some Theory and Evidence.” Journal of Development Economics 127: 169-186.

Yin, S. 2007. “Gender Disparities in Health and Mortality.” Population Reference Bureau (website). November 9, 2007. www.prb.org/Publications/Articles/2007/genderdisparities.aspx. 
Zang, E., and H. Zheng. 2018. “Does the Sex Ratio at Sexual Maturity Affect Men’s LaterLife Mortality Risks? Evidence from Historical China.” Social Science and Medicine 202: 61-69.

Zhong, S., I. Shalev, D. Koh, R. P. Ebstein, and S. H. Chew. 2018. “Competitiveness and Stress.” International Economic Review 59, no. 3: 1263-1281. 


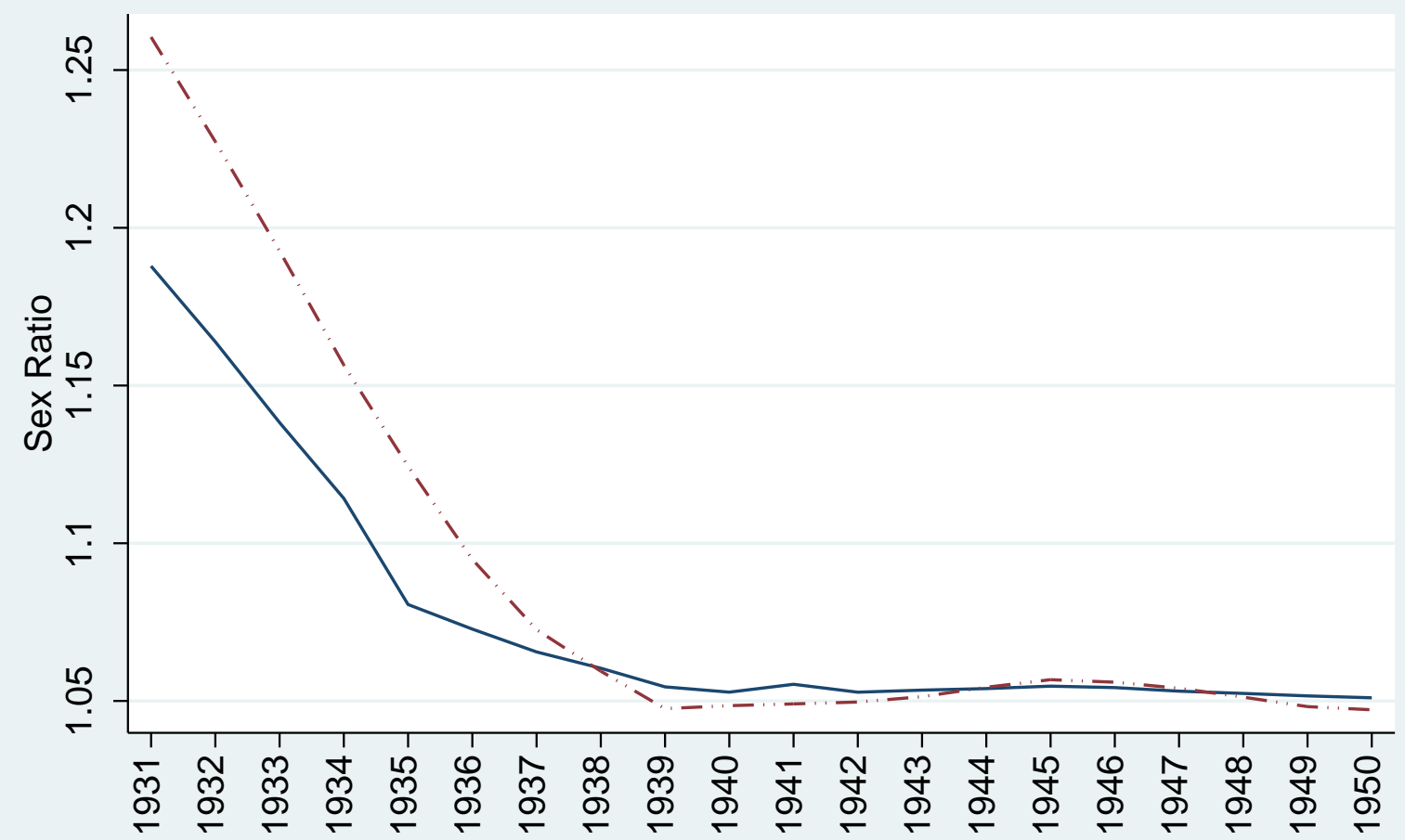

Birth Cohort

$$
\text { Age } 30 \quad-\cdots-\text { Age } 35
$$

Figure 1. National age-specific sex ratios by birth cohort.

Note. The sex ratio at ages 30 and 35 is the ratio of men to women who were 25-34 and 3039 when each cohort reached age 30 and 35 respectively. 
(A) Sex ratio at age 30

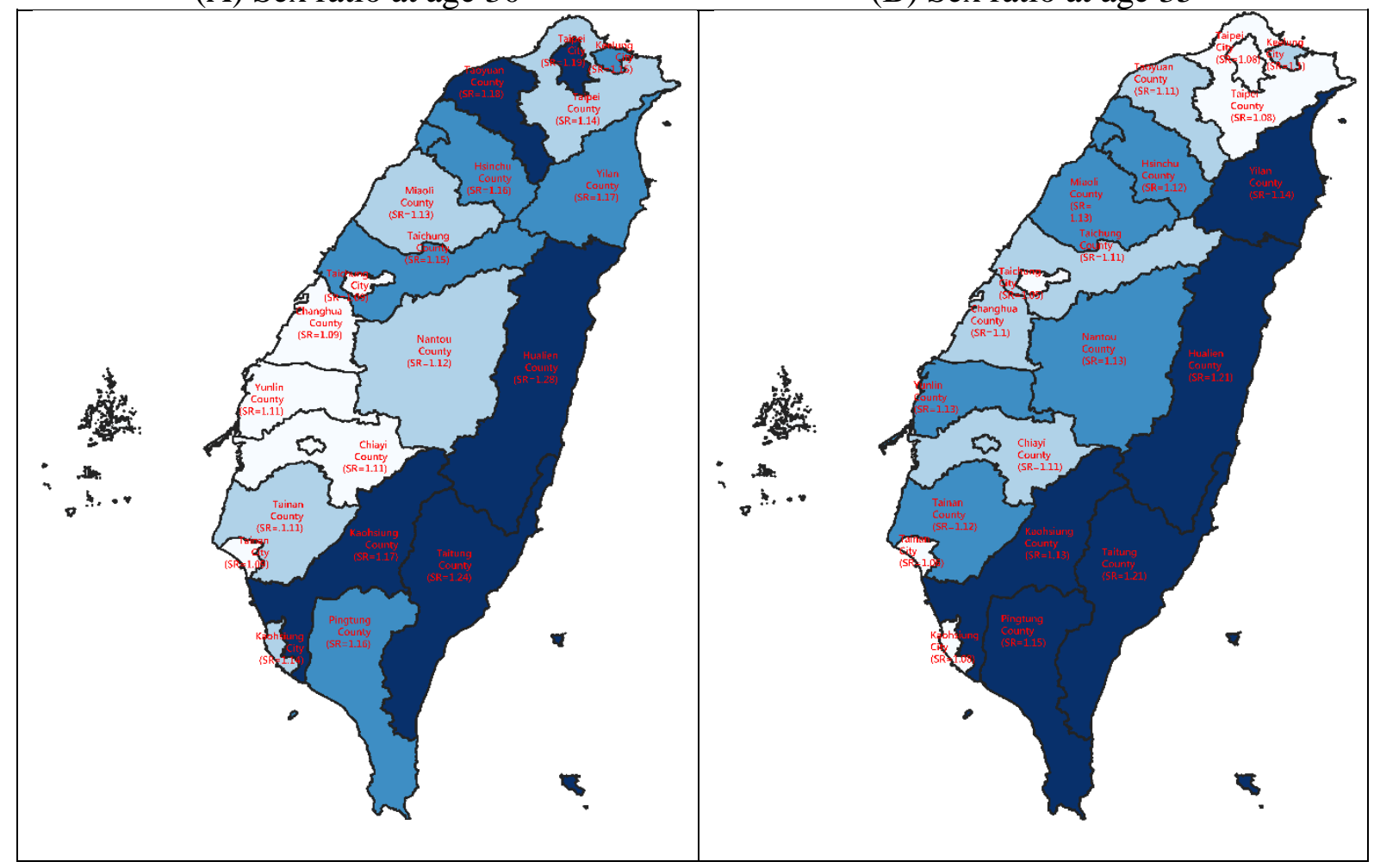

Figure 2. Age-specific sex ratios by county.

Note. The figure shows age-specific sex ratios in each county, averaged across birth cohorts 1931-1950. The sex ratio at ages 30 and 35 is the ratio of men to women who were 25-34 and 30-39 when each cohort reached age 30 and 35 respectively. Each age-specific sex ratio is divided into four quarters, with darker colors indicating counties with higher sex ratios. For age 30: 1st quarter: $<1.07$; 2nd quarter: 1.07 1.12; 3rd quarter: 1.12 1.14; 4th quarter: $>1.14$. For age 35, the cutoff points are the following: 1st quarter: $<1.02$; 2nd quarter: 1.02 1.11; 3rd quarter: 1.11 1.15; 4th quarter: >1.15. 


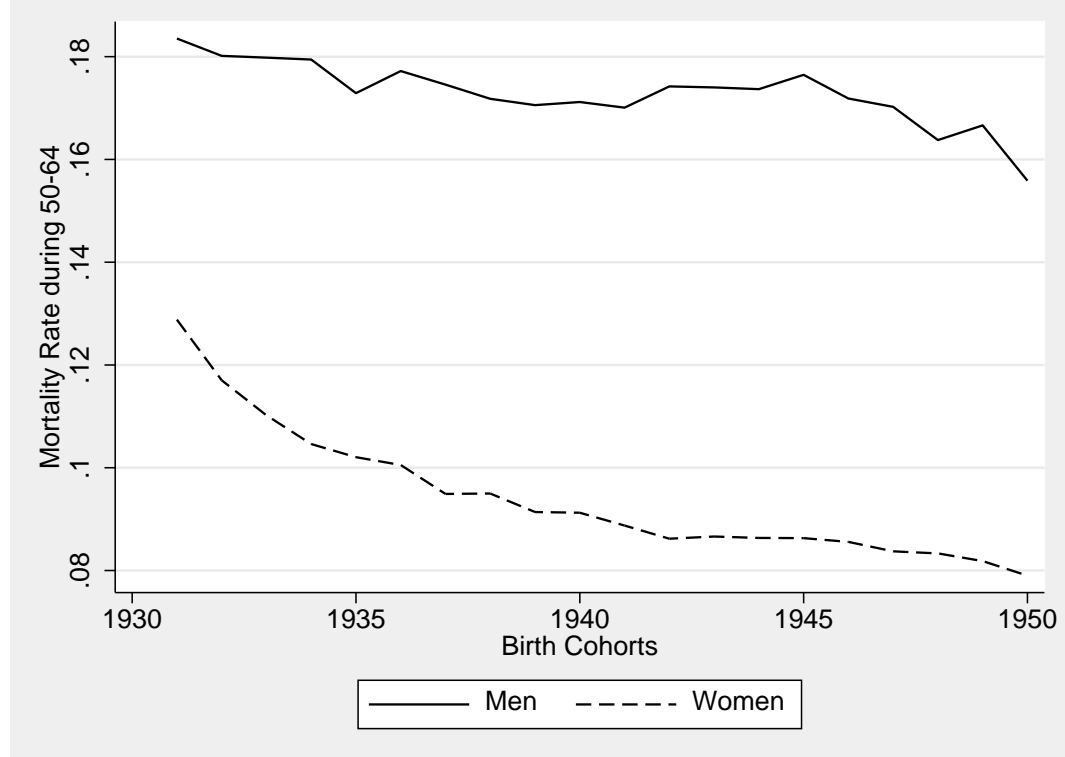

Figure 3. Trend in mortality rate at ages 50-64 by sex and cohort.

Note: The authors' calculation is based on the national death registry maintained by the Ministry of Health and Welfare. 
(A) Mortality Effect at Age 50-54

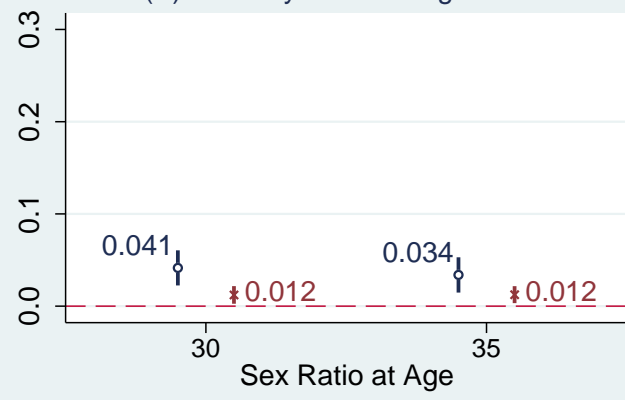

(C) Mortality Effect at Age 60-64

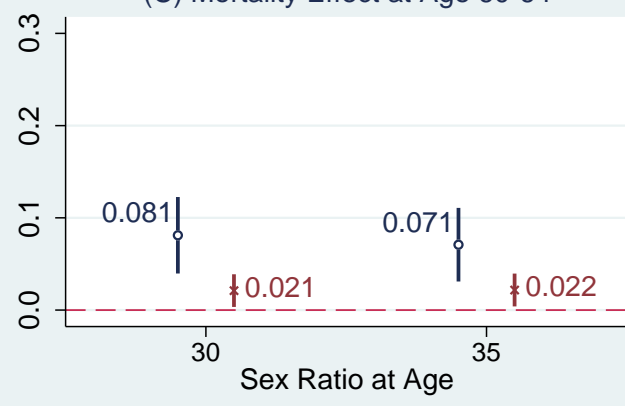

(B) Mortality Effect at Age 55-59

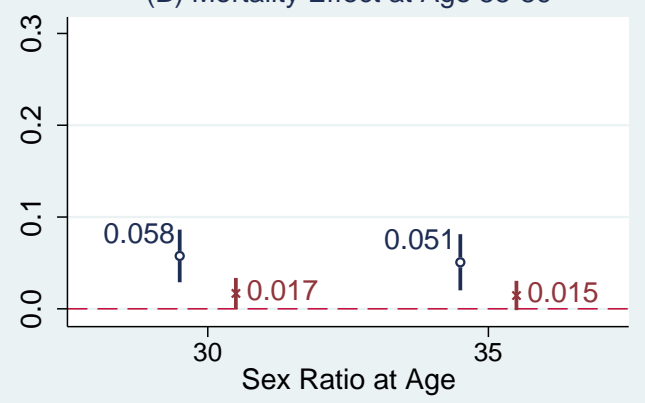

(D) Mortality Effect at Age 50-64

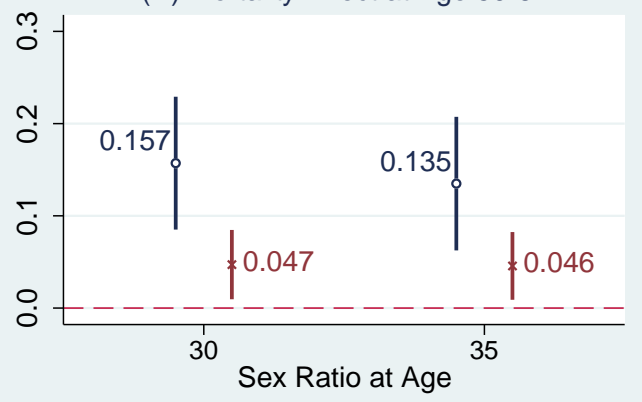

Figure 4. Ordinary least squares estimates of the sex-ratio effect on age-specific mortality rates.

Note. The dependent variables are mortality rates at ages 50-54 (panel A), 55-59 (panel B), 60-64 (panel C), and 50-64 (panel D). Point estimates with 95\% confidence intervals are shown. Robust standard errors clustered at the county have been used to construct the confidence interval. Circles and crosses indicate point estimates for men and women respectively. All estimates have been obtained from separate regressions. The sex ratio at ages 30 and 35 is the ratio of men to women who were 25-34 and 30-39 when each cohort turned 30 and 35 respectively. All regressions additionally control for log of prime-age (2064) men, industry male ratio, and share of risky jobs at each county at the corresponding age and a full set of county and birth cohort dummy variables. The sample includes birth cohorts between 1931 and 1950 across 20 counties. See Table A1 for estimation details. 
(A) Mortality Effect at Age 50-54

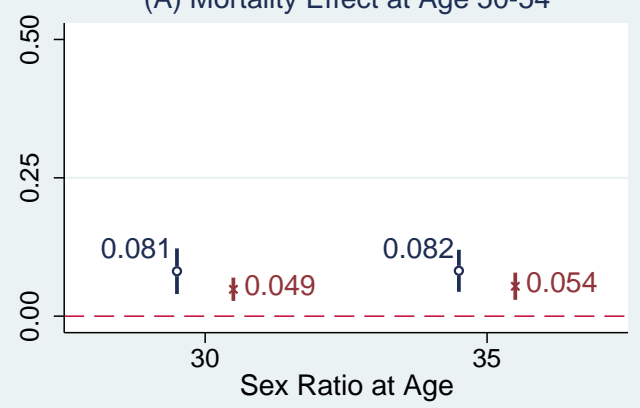

(C) Mortality Effect at Age 60-64

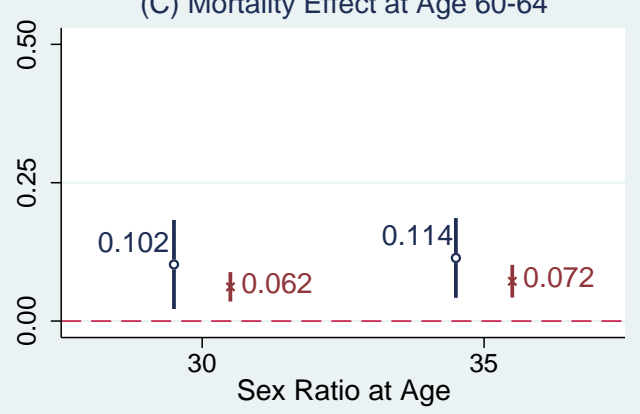

(B) Mortality Effect at Age 55-59

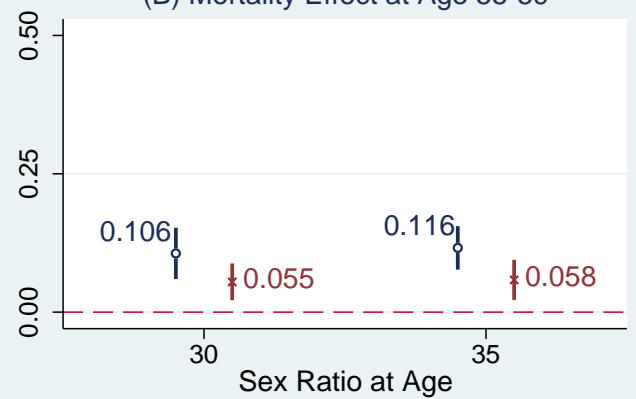

(D) Mortality Effect at Age 50-64

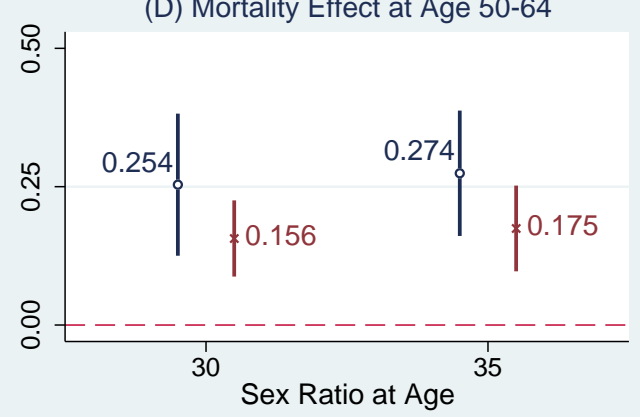

Figure 5. Two-stage least squares estimates of the sex-ratio effect on age-specific mortality rates.

Note. The dependent variables are mortality rates at ages 50-54 (panel A), 55-59 (panel B), 60-64 (panel C), and 50-64 (panel D). Point estimates with 95\% confidence intervals are shown. Robust standard errors clustered at the county have been used to construct the confidence intervals. Circles and crosses indicate point estimates for men and women respectively. All estimates have been obtained from separate regressions. The sex ratio at age 30 and 35 is the ratio of men to women who were 25-34 and 30-39 when each cohort turned 30 and 35 respectively. The instrumental variable is the log of mainland Chinese men interacted with the gender differential in the estimated global mortality rate at age 20 when each cohort reached age 20. All regressions additionally control for the log of prime-age (2064) men, industry male ratio, and share of risky jobs at each county at the corresponding age and a full set of county and birth cohort dummy variables. The sample includes birth cohorts between 1931 and 1950 across 20 counties. See Table A1 for estimation details.

Mortality rates and sex ratios are the authors' own imputations. The data relating to mainland Chinese men were drawn from the 1956 Population and Housing Census. Gender differentials in mortality were obtained from various abridged life tables published by the Ministry of the Interior in Taiwan. 

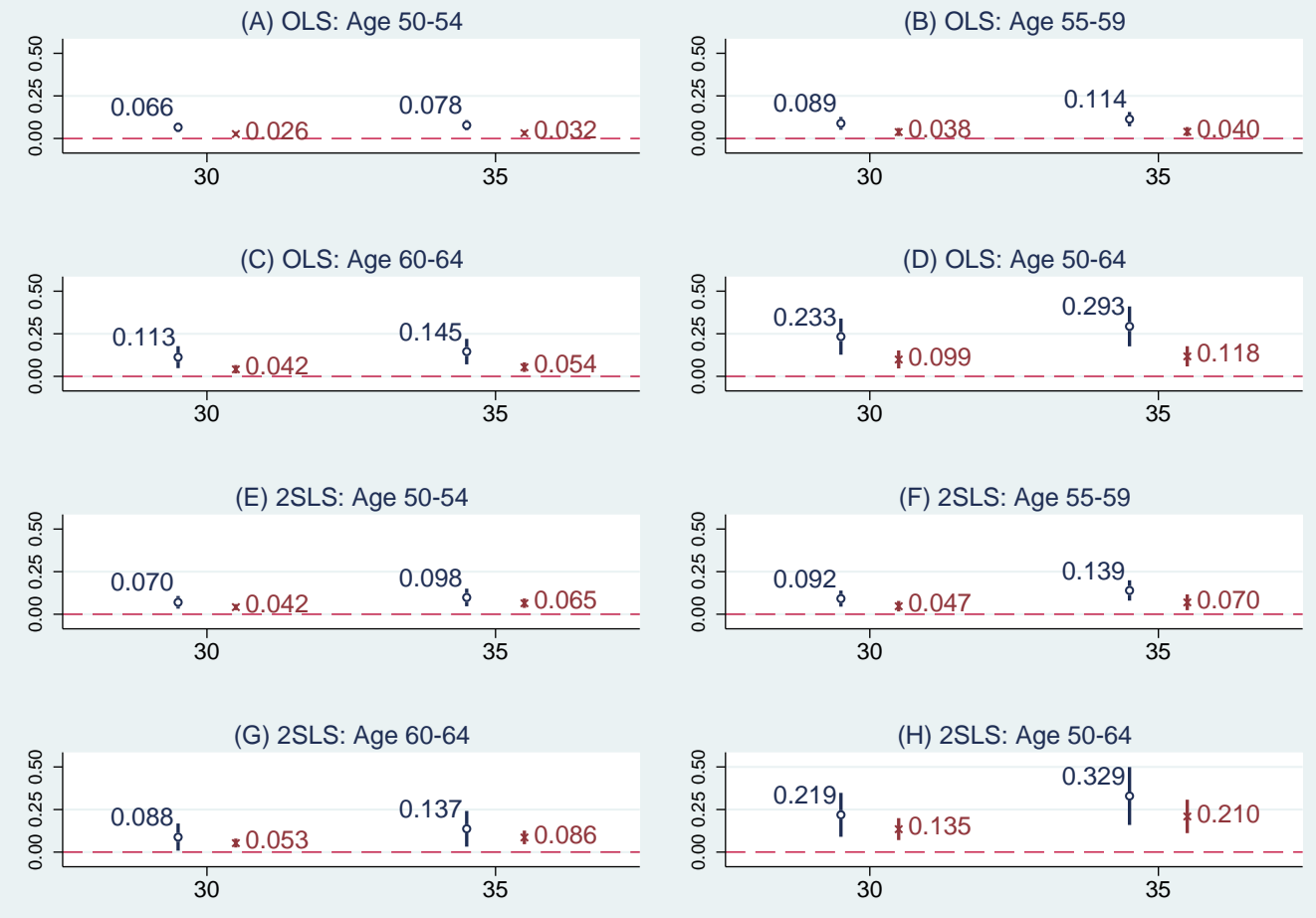

Figure 6. Estimates of the mortality effect using sex ratios with a wide age range (15-49).

Note. Dependent variables are mortality rates at ages 50-54, 55-59, 60-64, and 50-64.

Point estimates with 95\% confidence intervals are shown. Robust standard errors clustered at the county have been used to construct the confidence intervals. Circles and crosses indicate point estimates for men and women respectively. All estimates have been obtained from separate regressions. The sex ratio at ages 30 and 35 is the ratio of men to women who were 15-49 when each cohort turned 30 and 35 respectively. In panels (E), (F), (G), and (H), the instrumental variable is the log of mainland Chinese men interacted with the gender differential in the estimated global mortality rate at age 20 when each cohort turned 20. All regressions additionally control for the log of prime-age (20-64) men, industry male ratio, and share of risky jobs at each county at the corresponding age and a full set of county and birth cohort dummy variables. The sample includes birth cohorts between 1931 and 1950 across 20 counties. See Table A4 for estimation details.

Mortality rates and sex ratios are the authors' own imputations. The data relating to mainland Chinese men were drawn from the 1956 Population and Housing Census. Gender differentials in mortality were obtained from various abridged life tables published by the Ministry of the Interior in Taiwan. 
(A) CESD

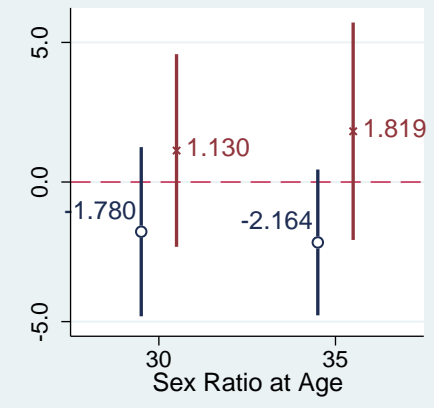

(D) High Blood Pressure

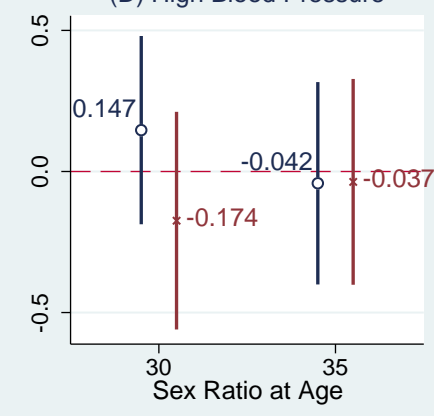

(B) Cancers

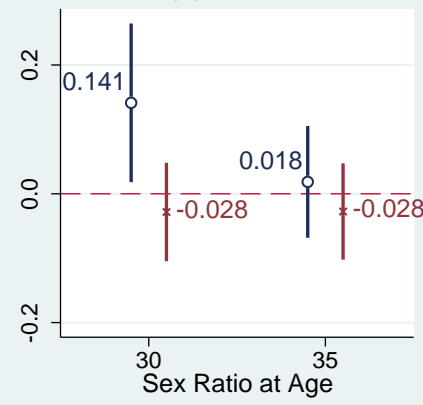

(E) Stroke

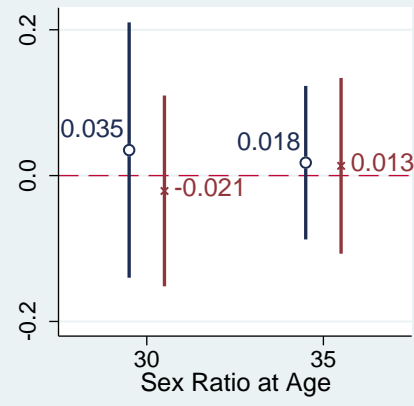

(C) Heart Diseases

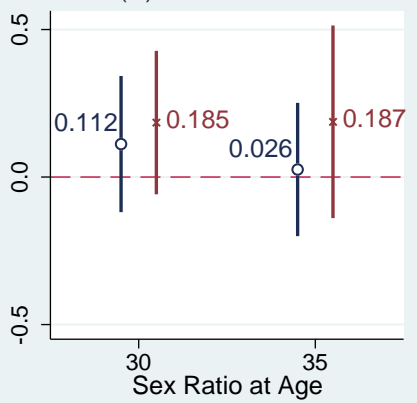

(F) Diabetes

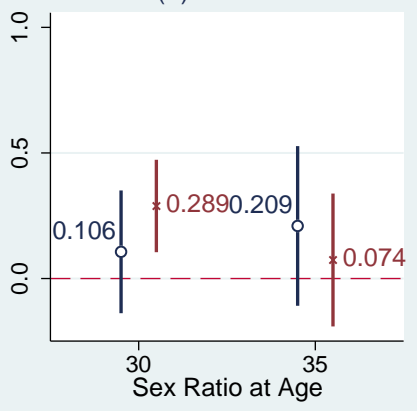

Figure 7. Ordinary least squares estimates of the sex-ratio effect on other health outcomes.

Note. The Center for Epidemiologic Studies Depression Scale (CES-D) measures depression with a score ranging from 0 (low depression) to 30 (high depression). All other dependent variables are dummy variables indicating whether a person has the respective medical condition.

Point estimates with 95\% confidence intervals are shown. Robust standard errors clustered at the county have been used to construct the confidence intervals. Circles and crosses indicate point estimates for men and women respectively. All estimates have been obtained from separate regressions. The sex ratio at ages 30 and 35 is the ratio of men to women who were 25-34 and 30-39 when each cohort turned 30 and 35 respectively. All regressions additionally control for age, age squared, log of prime-age (20-64) men, industry male ratio, share of risky jobs at each county at the corresponding age, a full set of county and birth cohort dummy variables, and a dummy variable indicating the sample drawn in 2003. The sample includes birth cohorts born between 1929 and 1953 across 20 counties. See Table A5 for the estimation details.

Health outcome data were drawn from the Health and Living Status of the Middle-Aged and Elderly Survey conducted in Taiwan in 1996 and 2003. Sex ratios are the authors' own imputations. Gender differentials in mortality were obtained from various abridged life tables published by the Ministry of the Interior in Taiwan. 


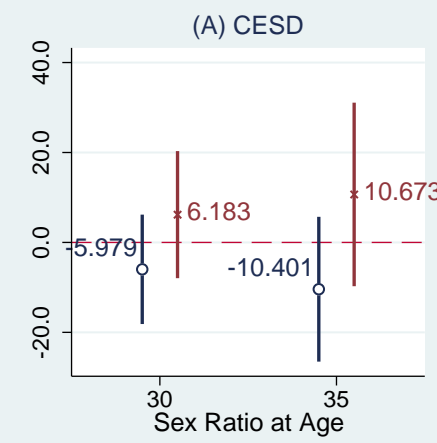

(B) Cancers

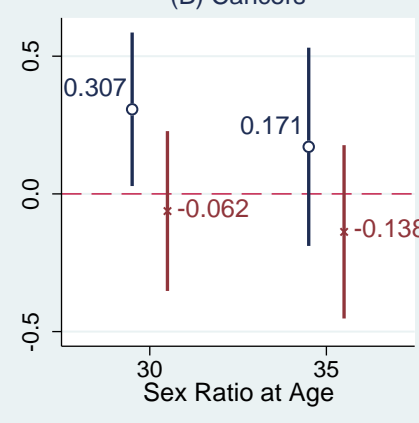

(E) Stroke

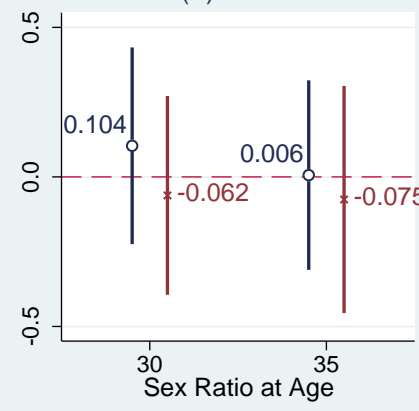

(C) Heart Diseases

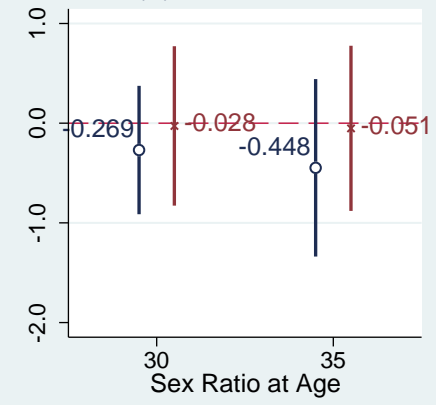

(F) Diabetes

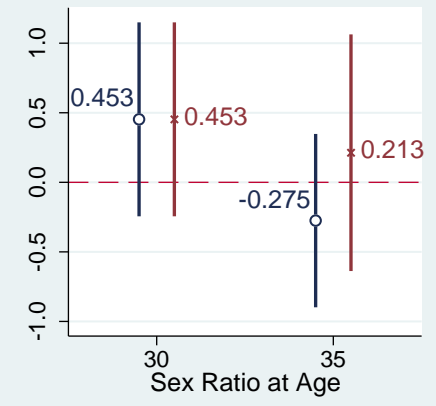

Figure 8. Two-stage least squares estimates of the sex-ratio effect on other health outcomes.

Note. The CES-D measures depression with a score ranging from 0 (low depression) to 30 (high depression). All other dependent variables are dummy variables indicating whether a person has the respective medical condition. Point estimates with 95\% confidence intervals are shown. Robust standard errors clustered at the county have been used to construct the confidence intervals. Circles and crosses indicate point estimates for men and women respectively. The instrumental variable is the log of mainland Chinese men interacted with the gender differential in the estimated global mortality rate at age 20 when each cohort turned 20. All estimates have been obtained from separate regressions. The sex ratio at ages 30 and 35 is the ratio of men to women who were 25-34 and 30-39 when each cohort reached age 30 and 35 respectively. All regressions additionally control for age, age squared, log of prime-age (20-64) men, industry male ratio, share of risky jobs at each county at the corresponding age, a full set of county and birth cohort dummy variables, and a dummy variable indicating the sample drawn in 2003. The sample includes birth cohorts between 1929 and 1953 across 20 counties. See Table A5 for the estimation details.

Health outcome data were derived from the Health and Living Status of the Middle-Aged and Elderly Survey done in Taiwan in 1996 and 2003. Sex ratios are the authors' own imputations. The data relating to mainland Chinese men were drawn from the 1956 Population and Housing Census. Gender differentials in mortality were obtained from various abridged life tables published by the Ministry of the Interior in Taiwan. 

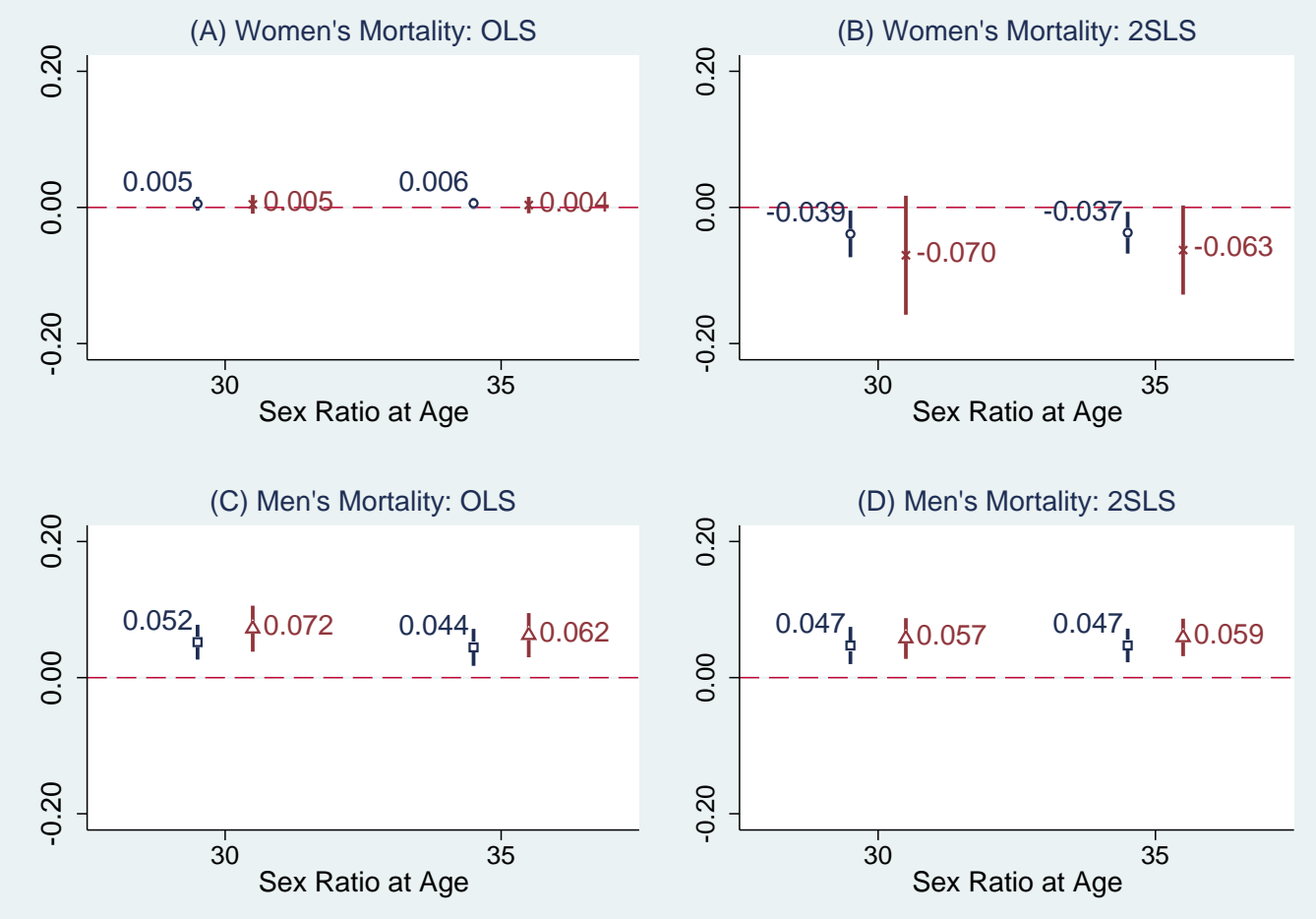

Figure 9. Widowhood effect test.

Note. The dependent variables in panels (A) and (B) are women's mortality rates at ages 5054 (circle) and 55-59 (cross). The dependent variables in panels (C) and (D) are men's mortality rates at ages 55-59 (square) and 60-64 (triangle). In the regressions of women's mortality at ages 50-54 and 50-59, men's mortality at ages 55-59 and 60-64 has respectively been further controlled to test for the widowhood effect. In the regressions of men's mortality at ages 55-59 and 60-64, women's mortality at ages 50-54 and 55-59 has respectively been further controlled to test the widowerhood effect. Point estimates with $95 \%$ confidence intervals are shown. Robust standard errors clustered at the county have been used to construct the confidence intervals. All estimates have been obtained from separate regressions. The sex ratio at ages 30 and 35 is the ratio of men to women who were 25-34 and 30-39 when each cohort reached age 30 and 35 respectively. All regressions additionally control for the log of prime-age (20-64) men, industry male ratio, share of risky jobs at each county at the corresponding age, and a full set of county and birth cohort dummy variables. In panels (B) and (D), the instrumental variables are the log of mainland Chinese men interacted with the gender differential in the estimated global mortality rate at age 20 when each cohort turned 20 and the log of mainland Chinese men interacted with the gender differential in the estimated global mortality rate at age 30 when each cohort turned 30 . The sample includes birth cohorts between 1931 and 1950 across 20 counties. See Table A6 for the estimation details.

Mortality rates and sex ratios are the authors' own imputations. The data relating to mainland Chinese men were drawn from the 1956 Population and Housing Census. The global estimated mortality rates at age 20 for males and females were obtained from the Abridged Life Table for Males and Females, World Population Prospects 2019, United Nations, Population Division, Department of Economic and Social Affairs. 


\section{Appendix 1. Imputing the Sex Ratios}

We followed the method proposed by Chang (2013) to impute the sex ratios in the marriage market. We briefly describe the method below. Readers interested in more details should reference Chang (2013) directly.

The main difficulty in calculating the sex ratios using the household registration data is that military personnel, mostly men, was excluded until an executive order was issued in November 1968 requiring all military personnel to be included in the household registration system. In other words, the soldiers who followed Chiang Kai-shek to Taiwan were not included in the data until 1969, leading to a downward bias in the sex ratios before 1969.

To correct the bias, we first calculated the increases in the male population in the household registration data between 1968 and 1970 for each age group and county, based on the assumption that all military personnel was registered in this period. The second step was adding the increases in men back to the corresponding age-county cells for the years before 1969 with an adjustment for age-sex-specific mortality rates. 
Appendix 2. Tables and Figures

Table A1. Estimates of the Sex-Ratio Effect on Mortality Rates

Ordinary Least Squares (OLS)

Sex Ratio at Age

\begin{tabular}{|c|c|c|c|c|c|c|c|}
\hline & & & & \\
\hline$(1)$ & $(2)$ & (3) & (4) & (5) & (6) & $(7)$ & (8) \\
\hline Men & Women & Men & Women & Men & Women & Men & Women \\
\hline Age 30 & Age 30 & Age 35 & Age 35 & Age 30 & Age 30 & Age 35 & Age 35 \\
\hline \multicolumn{8}{|c|}{ Panel A: Mortality Rate at Age 50-54 } \\
\hline $\begin{array}{c}0.041 * * * \\
(0.009)\end{array}$ & $\begin{array}{c}0.012 * * \\
(0.005)\end{array}$ & $\begin{array}{c}0.034^{* * *} \\
(0.009)\end{array}$ & $\begin{array}{c}0.012^{* *} \\
(0.004)\end{array}$ & $\begin{array}{c}0.081^{* * *} \\
(0.021)\end{array}$ & $\begin{array}{c}0.049 * * * \\
(0.011)\end{array}$ & $\begin{array}{c}0.082^{* * *} \\
(0.019)\end{array}$ & $\begin{array}{c}0.054^{* * *} \\
(0.013)\end{array}$ \\
\hline \multicolumn{8}{|c|}{ Panel B: Mortality Rate at Age 55-59 } \\
\hline $\begin{array}{c}0.058 * * * \\
(0.014)\end{array}$ & $\begin{array}{l}0.017 * \\
(0.008)\end{array}$ & $\begin{array}{c}0.051 * * * \\
(0.015)\end{array}$ & $\begin{array}{l}0.015^{*} \\
(0.008)\end{array}$ & $\begin{array}{c}0.106^{* * *} \\
(0.024)\end{array}$ & $\begin{array}{c}0.055^{* * *} \\
(0.017)\end{array}$ & $\begin{array}{c}0.116^{* * *} \\
(0.020)\end{array}$ & $\begin{array}{c}0.058 * * * \\
(0.018)\end{array}$ \\
\hline \multicolumn{8}{|c|}{ Panel C: Mortality Rate at Age 60-64 } \\
\hline $\begin{array}{c}0.081^{* * *} \\
(0.020)\end{array}$ & $\begin{array}{c}0.021^{* *} \\
(0.008)\end{array}$ & $\begin{array}{c}0.071^{* * *} \\
(0.019)\end{array}$ & $\begin{array}{c}0.022 * * \\
(0.009)\end{array}$ & $\begin{array}{c}0.102 * * \\
(0.041)\end{array}$ & $\begin{array}{c}0.062 * * * \\
(0.014)\end{array}$ & $\begin{array}{c}0.114 * * * \\
(0.037)\end{array}$ & $\begin{array}{c}0.072 * * * \\
(0.015)\end{array}$ \\
\hline \multicolumn{8}{|c|}{ Panel D: Mortality Rate at Age 50-64 } \\
\hline $\begin{array}{c}0.157 * * * \\
(0.034)\end{array}$ & $\begin{array}{c}0.047 * * \\
(0.018)\end{array}$ & $\begin{array}{c}0.135^{* * *} \\
(0.035)\end{array}$ & $\begin{array}{c}0.046 * * \\
(0.018)\end{array}$ & $\begin{array}{c}0.254 * * * \\
(0.066) \\
49.62\end{array}$ & $\begin{array}{c}0.156 * * * \\
(0.035) \\
50.57\end{array}$ & $\begin{array}{c}0.274 * * * \\
(0.058) \\
53.28\end{array}$ & $\begin{array}{c}0.175 * * * \\
(0.040) \\
55\end{array}$ \\
\hline 400 & 400 & 400 & 400 & 400 & 400 & 400 & 400 \\
\hline
\end{tabular}

Observations

Note: The dependent variables are mortality rates at the county-cohort level at ages 50-54 (panel A), 55-59 (panel B), 60-64 (panel C), and 50-64 (panel D). The instrumental variable is the log of mainland Chinese men interacted with the gender differential in the estimated global mortality rate at age 20 when each cohort turned 20. The sample includes birth cohorts between 1931 and 1950 across 20 counties. All

estimates were obtained from separate regressions. The sex ratio at ages 30 and 35 is the ratio of men to women who were 25-34 and 30-39 when each cohort reached age 30 and 35 respectively. All regressions control for the log of working-age (20-64) males, industry male ratio, share of risky jobs at the county level in each age group, and a full set of county and birth cohort dummy variables. Robust standard errors clustered at the county are in parentheses. ${ }^{* * *}, * *$, and * indicate significance at $1 \%, 5 \%$, and $10 \%$ respectively. Mortality rates and sex ratios are the authors' own imputations. The data relating to mainland Chinese men were drawn from the 1956 Population and Housing Census.

Estimated global mortality rates at age 20 for males and females were obtained from the Abridged Life Table for Males and Females, World Population Prospects 2019, United Nations, Population Division, Department of Economic and Social Affairs. 
Table A2. First-Stage Estimates

(1)

(2)

Sex Ratio at Age

Age 30

Age 35

Log of $M C M \times$ gender diff in

$59.107 * * *$

$55.962 * * *$ global mortality at age 20

(12.996)

(12.565)

Note: The dependent variables are the sex ratios at ages 30 (column 1) and 35 (column 2). They are measured as the ratios of men to women who respectively are 25-34 and 30-39 at the county level. The key explanatory variable is the log of MCM interacted with the gender differential in the estimated global mortality rate at age 20 when each cohort turned 20. All regressions control for the log of prime-age (20-64) men, industry male ratio, share of risky jobs at the county level in each age group, and a full set of county and birth cohort dummy variables. Robust standard errors clustered at the county are in parentheses. ***, $* *$, and $*$ indicate significance at $1 \%, 5 \%$, and $10 \%$.

The sex ratios are the authors' own imputations. The data relating to mainland Chinese men were drawn from the 1956 Population and Housing Census. Estimated global mortality rates at age 20 for males and females were obtained from the Abridged Life Table for Males and Females, World Population Prospects 2019, United Nations, Population Division, Department of Economic and Social Affairs. 
Table A3. Two-Stage Least Squares Estimates Using Worldwide Gender Difference in Mortality Rate at Age $\mathbf{3 0}$ as Instrument

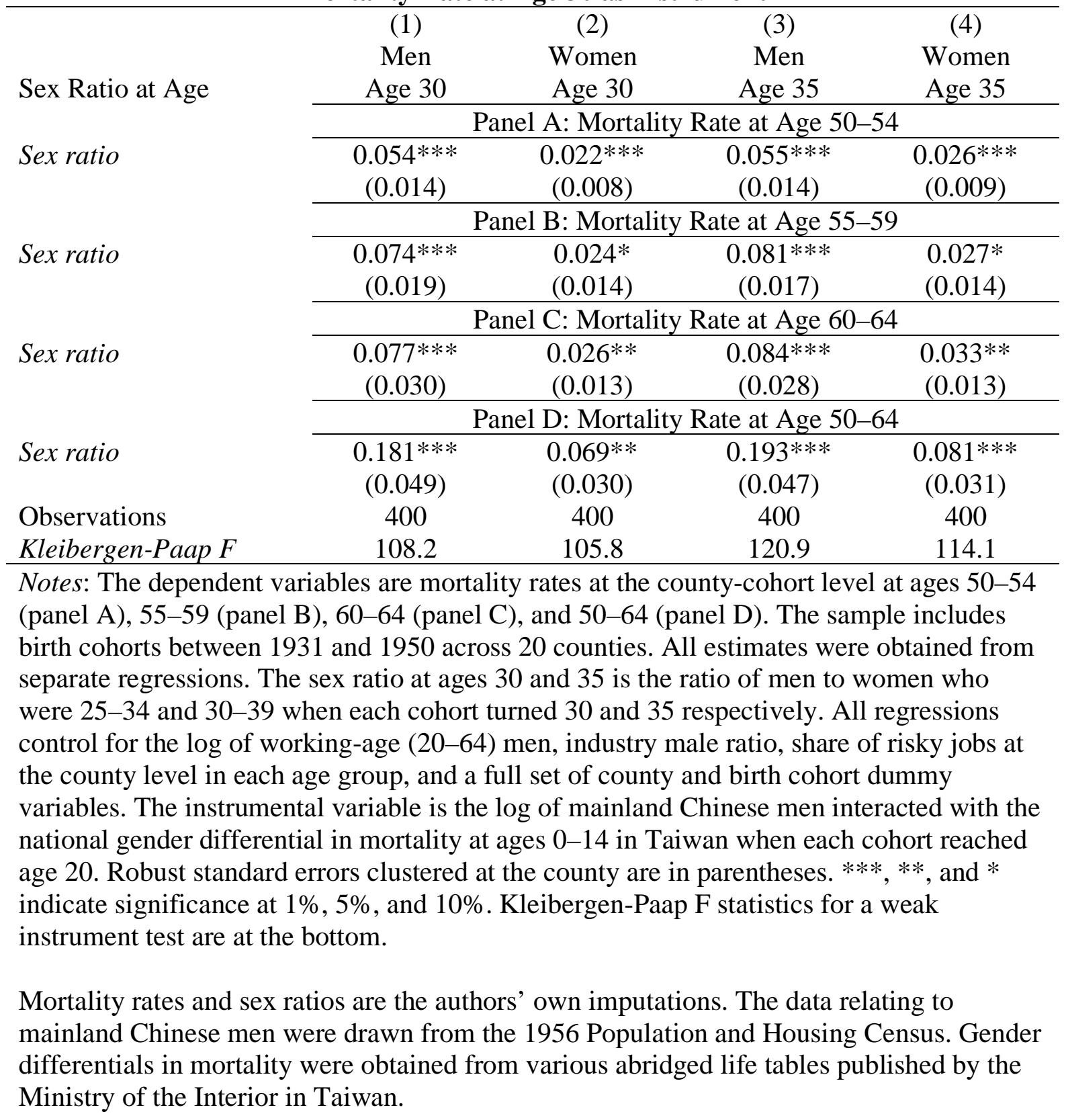


Table A4. Estimates of the Mortality Effect Using Sex Ratios with a Wide Age Range (15-49)

Ordinary Least Squares

\begin{tabular}{|c|c|c|c|c|c|c|c|c|}
\hline & \multicolumn{4}{|c|}{ Ordinary Least Squares } & \multicolumn{4}{|c|}{ Two-Stage Least Squares } \\
\hline & (1) & (2) & (3) & (4) & (5) & (6) & (7) & (8) \\
\hline & Men & Women & Men & Women & Men & Women & Men & Women \\
\hline \multirow[t]{2}{*}{ Sex Ratio at Age } & Age 30 & Age 30 & Age 35 & Age 35 & Age 30 & Age 30 & Age 35 & Age 35 \\
\hline & \multicolumn{8}{|c|}{ Panel A: Mortality Rate at Age 50-54 } \\
\hline \multirow[t]{2}{*}{ Sex ratio } & $\begin{array}{c}0.066 * * * \\
(0.013)\end{array}$ & $\begin{array}{c}0.026 * * * \\
(0.006)\end{array}$ & $\begin{array}{c}0.078 * * * \\
(0.014)\end{array}$ & $\begin{array}{c}0.032 * * * \\
(0.007)\end{array}$ & $\begin{array}{c}0.070 * * * \\
(0.019)\end{array}$ & $\begin{array}{c}0.042^{* * *} \\
(0.009)\end{array}$ & $\begin{array}{c}0.098 * * * \\
(0.026)\end{array}$ & $\begin{array}{c}0.065^{* * * *} \\
(0.014)\end{array}$ \\
\hline & \multicolumn{8}{|c|}{ Panel B: Mortality Rate at Age 55-59 } \\
\hline \multirow[t]{2}{*}{ Sex ratio } & $\begin{array}{c}0.089 * * * \\
(0.018)\end{array}$ & $\begin{array}{c}0.038 * * * \\
(0.011)\end{array}$ & $\begin{array}{c}0.114 * * * \\
(0.020)\end{array}$ & $\begin{array}{c}0.040^{* * *} \\
(0.013)\end{array}$ & $\begin{array}{c}0.092 * * * \\
(0.024)\end{array}$ & $\begin{array}{c}0.047 * * * \\
(0.016)\end{array}$ & $\begin{array}{c}0.139 * * * \\
(0.030)\end{array}$ & $\begin{array}{c}0.070 * * * \\
(0.024)\end{array}$ \\
\hline & \multicolumn{8}{|c|}{ Panel C: Mortality Rate at Age 60-64 } \\
\hline \multirow[t]{2}{*}{ Sex ratio } & $\begin{array}{c}0.113 * * * \\
(0.031)\end{array}$ & $\begin{array}{c}0.042 * * * \\
(0.012)\end{array}$ & $\begin{array}{c}0.145 * * * \\
(0.036)\end{array}$ & $\begin{array}{c}0.054 * * * \\
(0.013)\end{array}$ & $\begin{array}{c}0.088^{* *} \\
(0.041)\end{array}$ & $\begin{array}{c}0.053^{* * *} \\
(0.013)\end{array}$ & $\begin{array}{c}0.137 * * \\
(0.053)\end{array}$ & $\begin{array}{c}0.086^{* * *} \\
(0.020)\end{array}$ \\
\hline & \multicolumn{8}{|c|}{ Panel D: Mortality Rate at Age 50-64 } \\
\hline Sex ratio & $\begin{array}{c}0.233 * * * \\
(0.051)\end{array}$ & $\begin{array}{c}0.099 * * * \\
(0.025)\end{array}$ & $\begin{array}{c}0.293 * * * \\
(0.056)\end{array}$ & $\begin{array}{c}0.118^{* * *} \\
(0.028)\end{array}$ & $\begin{array}{c}0.219 * * * \\
(0.066)\end{array}$ & $\begin{array}{c}0.135^{* * *} \\
(0.033)\end{array}$ & $\begin{array}{c}0.329 * * * \\
(0.087)\end{array}$ & $\begin{array}{c}0.210 * * * \\
(0.050)\end{array}$ \\
\hline Kleibergen-Paap F & & & & & 187.8 & 191.4 & 121.4 & 124.9 \\
\hline Observations & 400 & 400 & 400 & 400 & 400 & 400 & 400 & 400 \\
\hline
\end{tabular}

Notes: The dependent variables are mortality rates at the county-cohort level at ages 50-54 (panel A), 55-59 (panel B), 6064 (panel C), and 50-64 (panel D). The instrumental variable is the log of mainland Chinese men interacted with the gender differential in the estimated global mortality rate at age 20 when each cohort turned 20 . The sample includes birth cohorts born between 1931 and 1950 across 20 counties. All estimates were obtained from separate regressions. The sex ratio at ages 30 and 35 is the ratio of men to women who were 15-49 when each cohort turned 30 and 35 respectively. All regressions control for the log of working-age (20-64) men, industry male ratio, share of risky jobs at the county level in each age group, and a full set of county and birth cohort dummy variables. Robust standard errors clustered at the county are in parentheses. ${ }^{* * *}, * *$, and $*$ indicate significance at $1 \%, 5 \%$, and $10 \%$ respectively.

Mortality rates and sex ratios are the authors’ own imputations. The data relating to mainland Chinese men were drawn from the 1956 Population and Housing Census. Estimated global mortality rates at age 20 for males and females were obtained from the Abridged Life Table for Males and Females, World Population Prospects 2019, United Nations, Population Division, Department of Economic and Social Affairs. 
Table A5. OLS and 2SLS Estimates of the Sex-Ratio Effect on Other Health Outcomes

\begin{tabular}{|c|c|c|c|c|c|c|c|c|}
\hline & OLS & OLS & OLS & OLS & 2SLS & 2SLS & 2SLS & 2SLS \\
\hline & Men & Women & Men & Women & Men & Women & Men & Women \\
\hline \multirow[t]{2}{*}{ Sex Ratio at Age } & Age 30 & Age 30 & Age 35 & Age 35 & Age 30 & Age 30 & Age 35 & Age 35 \\
\hline & \multicolumn{8}{|c|}{ Panel A: CES-D } \\
\hline Sex ratio & $\begin{array}{l}-1.780 \\
(1.448)\end{array}$ & $\begin{array}{c}1.130 \\
(1.649)\end{array}$ & $\begin{array}{l}-2.164 * \\
(1.248)\end{array}$ & $\begin{array}{l}1.819 \\
(1.860)\end{array}$ & $\begin{array}{l}-5.979 \\
(6.206)\end{array}$ & $\begin{array}{c}6.183 \\
(7.210)\end{array}$ & $\begin{array}{l}-10.401 \\
(8.213)\end{array}$ & $\begin{array}{c}10.673 \\
(10.412)\end{array}$ \\
\hline Observations & 1,990 & 1,899 & 1,990 & 1,899 & 1,990 & 1,899 & 1,990 & 1,899 \\
\hline \multirow[t]{2}{*}{ Kleibergen-Paap F } & & & & & 25.94 & 24.20 & 14.99 & 13.33 \\
\hline & \multicolumn{8}{|c|}{ Panel B: Cancers } \\
\hline Sex ratio & $\begin{array}{c}0.141^{* *} \\
(0.059)\end{array}$ & $\begin{array}{c}-0.028 \\
(0.037)\end{array}$ & $\begin{array}{c}0.018 \\
(0.041)\end{array}$ & $\begin{array}{c}-0.028 \\
(0.036)\end{array}$ & $\begin{array}{c}0.307 * * \\
(0.142)\end{array}$ & $\begin{array}{c}-0.062 \\
(0.148)\end{array}$ & $\begin{array}{c}0.171 \\
(0.184)\end{array}$ & $\begin{array}{c}-0.138 \\
(0.161)\end{array}$ \\
\hline Observations & 2,081 & 1,980 & 2,081 & 1,980 & 2,081 & 1,980 & 2,081 & 1,980 \\
\hline \multirow[t]{2}{*}{ Kleibergen-Paap F } & & & & & 23.81 & 24.67 & 12.89 & 15.06 \\
\hline & \multicolumn{8}{|c|}{ Panel C: Heart Diseases } \\
\hline \multirow[t]{2}{*}{ Sex ratio } & 0.112 & 0.185 & 0.026 & 0.187 & -0.269 & -0.028 & -0.448 & -0.051 \\
\hline & $(0.110)$ & $(0.116)$ & $(0.108)$ & $(0.156)$ & $(0.328)$ & $(0.408)$ & $(0.454)$ & $(0.423)$ \\
\hline \multirow[t]{2}{*}{ Observations } & 2,081 & 1,980 & 2,081 & 1,980 & 2,081 & 1,980 & 2,081 & 1,980 \\
\hline & & & & & 23.81 & 24.67 & 12.89 & 15.06 \\
\hline \multirow{3}{*}{$\begin{array}{l}\text { Kleibergen-Paap F } \\
\text { Sex ratio }\end{array}$} & & & & Panel D: & Pressure & & & \\
\hline & 0.147 & -0.174 & -0.042 & -0.037 & $0.715^{*}$ & 1.095* & 0.494 & 1.735 \\
\hline & $(0.159)$ & $(0.184)$ & $(0.171)$ & $(0.174)$ & $(0.430)$ & $(0.642)$ & $(0.678)$ & (1.063) \\
\hline \multirow{3}{*}{$\begin{array}{l}\text { Observations } \\
\text { Kleibergen-Paap F }\end{array}$} & 2,081 & 1,980 & 2,081 & 1,980 & 2,081 & 1,980 & 2,081 & 1,980 \\
\hline & & & & & 23.81 & 24.67 & 12.89 & 15.06 \\
\hline & \multicolumn{8}{|c|}{ Panel E: Stroke } \\
\hline \multirow[t]{2}{*}{ Sex ratio } & 0.035 & -0.021 & 0.018 & 0.013 & 0.104 & -0.062 & 0.006 & -0.075 \\
\hline & $(0.084)$ & $(0.063)$ & $(0.050)$ & $(0.058)$ & $(0.168)$ & $(0.170)$ & $(0.162)$ & $(0.194)$ \\
\hline Observations & 2,081 & 1,976 & 2,081 & 1,976 & 2,081 & 1,976 & 2,081 & 1,976 \\
\hline \multirow[t]{2}{*}{ Kleibergen-Paap F } & & & & & 23.81 & 24.48 & 12.89 & 14.59 \\
\hline & \multicolumn{8}{|c|}{ Panel F: Diabetes } \\
\hline \multirow[t]{2}{*}{ Sex ratio } & 0.106 & $0.289 * * *$ & 0.209 & 0.074 & -0.270 & 0.453 & -0.275 & 0.213 \\
\hline & $(0.117)$ & $(0.088)$ & $(0.152)$ & $(0.126)$ & $(0.235)$ & $(0.356)$ & $(0.318)$ & $(0.434)$ \\
\hline Observations & 2,081 & 1,980 & 2,081 & 1,980 & 2,081 & 1,980 & 2,081 & 1,980 \\
\hline Kleibergen-Paap F & & & & & 23.81 & 24.67 & 12.89 & 15.06 \\
\hline
\end{tabular}

Notes: CES-D measures depression with a score ranging from 0 (low depression) to 30 (high depression). All other dependent variables are dummy variables indicating whether a person has the respective medical condition. All estimates were obtained from separate regressions. The sex ratio at ages 30 and 35 is the ratio of men to women who were $25-34$ and $30-39$ when each cohort turned 30 and 35 respectively. All regressions additionally control for age, age squared, the log of prime-age (20-64) men, industry male ratio, share of risky jobs at the county at the corresponding age, a full set of county and birth cohort dummy variables, and a dummy variable indicating the sample drawn in 2003 . The sample includes birth cohorts between 1929 and 1953 across 20 counties. Robust standard errors clustered at the county have been used to construct the confidence intervals. $* * *, * *$, and $*$ indicate significance at $1 \%, 5 \%$, and $10 \%$.

Health outcome data were drawn from the Health and Living Status of the Middle-Aged and Elderly Survey done in Taiwan in 1996 and 2003. Sex ratios are the authors' own imputations. 
Table A6. Widowhood Effect Test

\begin{tabular}{|c|c|c|c|c|}
\hline & (1) & (2) & (3) & (4) \\
\hline \multirow[t]{2}{*}{ Sex Ratio at Age } & Age 30 & Age 30 & Age 35 & Age 35 \\
\hline & \multicolumn{4}{|c|}{ Panel A: Women's Mortality: OLS } \\
\hline \multirow[t]{2}{*}{ Sex ratio } & 0.005 & 0.005 & 0.006 & 0.004 \\
\hline & $(0.005)$ & $(0.007)$ & $(0.004)$ & $(0.006)$ \\
\hline \multirow[t]{3}{*}{ Men's mortality } & $0.118 * * *$ & $0.151 * * *$ & $0.127 * * *$ & $0.155^{* * *}$ \\
\hline & $(0.041)$ & $(0.029)$ & $(0.040)$ & $(0.029)$ \\
\hline & \multicolumn{4}{|c|}{ Panel B: Women’s Mortality: 2SLS } \\
\hline \multirow[t]{2}{*}{ Sex ratio } & $-0.039 * *$ & -0.070 & $-0.037 * *$ & $-0.063 *$ \\
\hline & $(0.017)$ & $(0.045)$ & $(0.016)$ & $(0.033)$ \\
\hline \multirow[t]{2}{*}{ Men’s mortality } & $0.825 * * *$ & 1.222 & $0.785 * * *$ & $1.061^{* *}$ \\
\hline & $(0.263)$ & $(0.781)$ & $(0.216)$ & $(0.525)$ \\
\hline Outcome: Women’s Mortality & Age $50-54$ & Age 55-59 & Age $50-54$ & Age $55-59$ \\
\hline Control: Men’s Mortality & Age $55-59$ & Age 60-64 & Age 55-59 & Age 60-64 \\
\hline Observations & 400 & 400 & 400 & 400 \\
\hline \multirow[t]{2}{*}{ Kleibergen-Paap F } & 7.892 & 2.052 & 9.390 & 3.369 \\
\hline & \multicolumn{4}{|c|}{ Panel C: Men’s Mortality: OLS } \\
\hline \multirow[t]{2}{*}{ Sex ratio } & $0.052 * * *$ & $0.072 * * *$ & $0.044^{* * *}$ & $0.062 * * *$ \\
\hline & $(0.012)$ & $(0.016)$ & $(0.013)$ & $(0.016)$ \\
\hline \multirow[t]{3}{*}{ Women's mortality } & $0.447 * * *$ & $0.547 * * *$ & $0.499 * * *$ & $0.587 * * *$ \\
\hline & $(0.147)$ & $(0.147)$ & $(0.155)$ & $(0.146)$ \\
\hline & \multicolumn{4}{|c|}{ Panel D: Men’s Mortality: 2SLS } \\
\hline \multirow[t]{2}{*}{ Sex ratio } & $0.047 * * *$ & $0.057 * * *$ & $0.047 * * *$ & $0.059 * * *$ \\
\hline & $(0.014)$ & $(0.015)$ & $(0.013)$ & $(0.014)$ \\
\hline \multirow[t]{2}{*}{ Women's mortality } & $1.213^{* * *}$ & 0.818 & $1.274 * * *$ & $0.943 * *$ \\
\hline & $(0.387)$ & $(0.523)$ & $(0.350)$ & $(0.467)$ \\
\hline Outcome: Men’s Mortality & Age 55-59 & Age 60-64 & Age 55-59 & Age 60-64 \\
\hline Control: Women’s Mortality & Age $50-54$ & Age 55-59 & Age 50-54 & Age 55-59 \\
\hline Observations & 400 & 400 & 400 & 400 \\
\hline Kleibergen-Paap F & 17.08 & 12.32 & 18.20 & 12.13 \\
\hline
\end{tabular}

Notes: The dependent variables in panels (A) and (B) are women's mortality rates at ages 50-54 and 55-59. The dependent variables in panels (C) and (D) are men's mortality rates at ages 55-59 and 60-64. In regressions of women's mortality at ages 50-54 and 50-59, men's mortality at ages 55-59 and 60-64 respectively is further controlled to test the widowhood effect. In regressions of men's mortality at ages 55-59 and 60-64, women's mortality at ages 50-54 and 55-59 is respectively further controlled to test the widowerhood effect. All estimates have been obtained from separate regressions. The sex ratio at ages 30 and 35 is the ratio of men to women who were 25-34 and 30-39 when each cohort turned 30 and 35 respectively. All regressions additionally control for the log of prime-age (20-64) men, industry male ratio, share of risky jobs at the county at the corresponding age, and a full set of county and birth cohort dummy variables. In panels (B) and (D), the instrumental variables are the log of mainland Chinese men interacted with the gender differential in the estimated global mortality rate at age 20 when each cohort turned 20 and the log of mainland Chinese men interacted with the gender differential in the estimated global mortality rate at age 30 when each cohort turned 30 . Robust standard errors clustered at the county have been used to construct the confidence interval. The sample includes birth cohorts born between 1931 and 1950 across 20 counties. ${ }^{* * *}, * *$, and $*$ indicate significance at $1 \%, 5 \%$, and $10 \%$.

Mortality rates and sex ratios are the authors' own imputations. The data relating to mainland Chinese men were drawn from the 1956 Population and Housing Census. Estimated global mortality rates at age 20 for males and females were obtained from the Abridged Life Table for Males and Females, World Population Prospects 2019, United Nations, Population Division, Department of Economic and Social Affairs. 
(A) Distribution of Chinese Mainlanders and Military Bases in 1956.

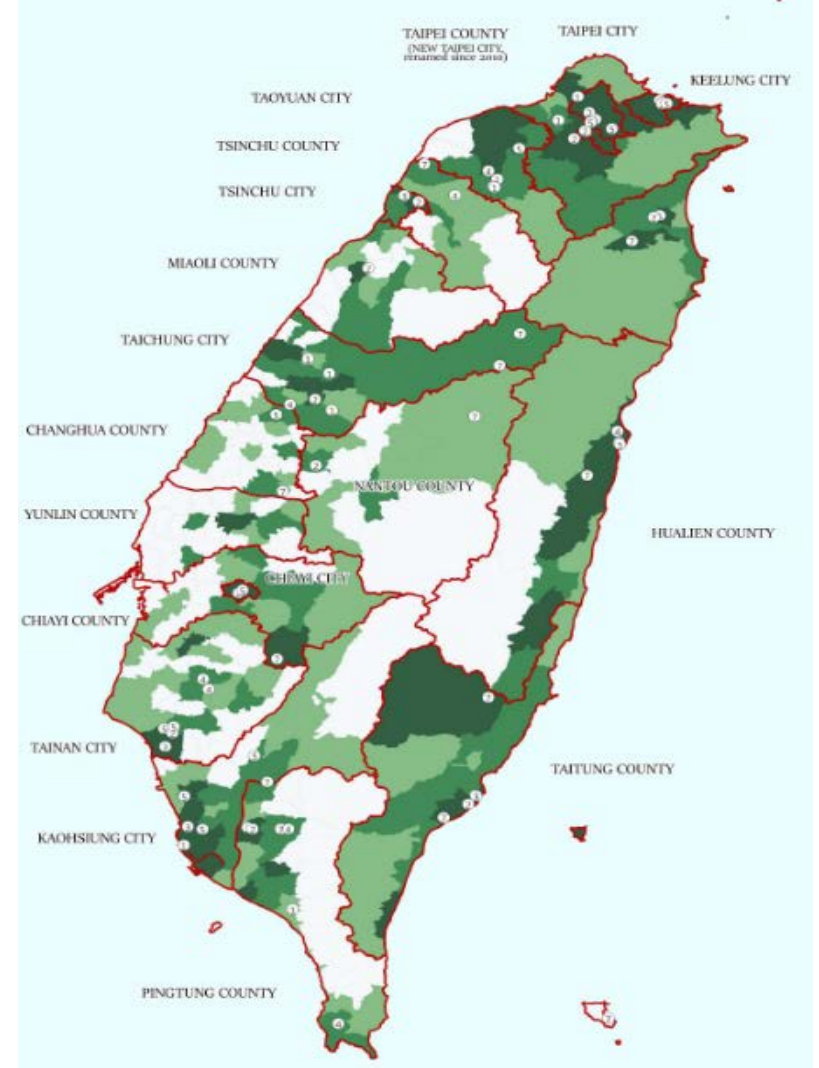

(B) Distribution of Chinese Mainlanders and Veterans

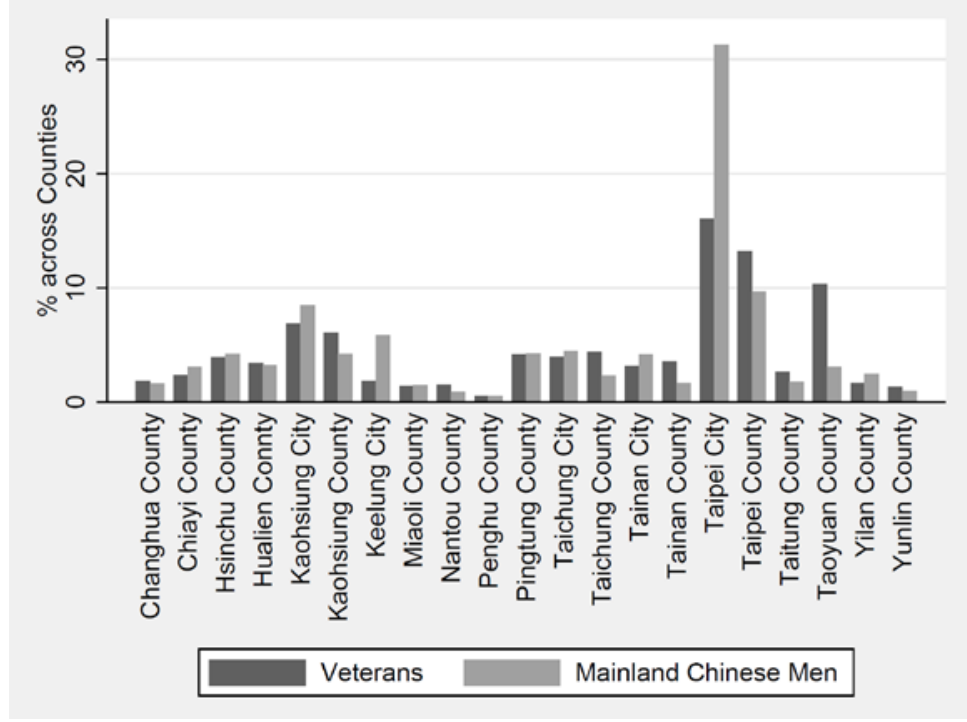

Figure A1. Distribution of Mainlanders, Military Bases, and Veterans.

Note: In (A), the green color indicates the percentage of Chinese mainlanders at the township level in 1956, with darker green indicating a higher percentage. The white circles indicate the following: 1 . military camp, 2. military police, 3. military base, 4 . recruit training center, 5. command, 6. headquarters, and 7. state farm. Image (B) shows the distribution of veterans across counties in 1996. The correlation coefficient between the two variables is as high as 0.802. Data were drawn from the Housing and Population Census of 1956 and Veteran Affairs Council, Taiwan. 


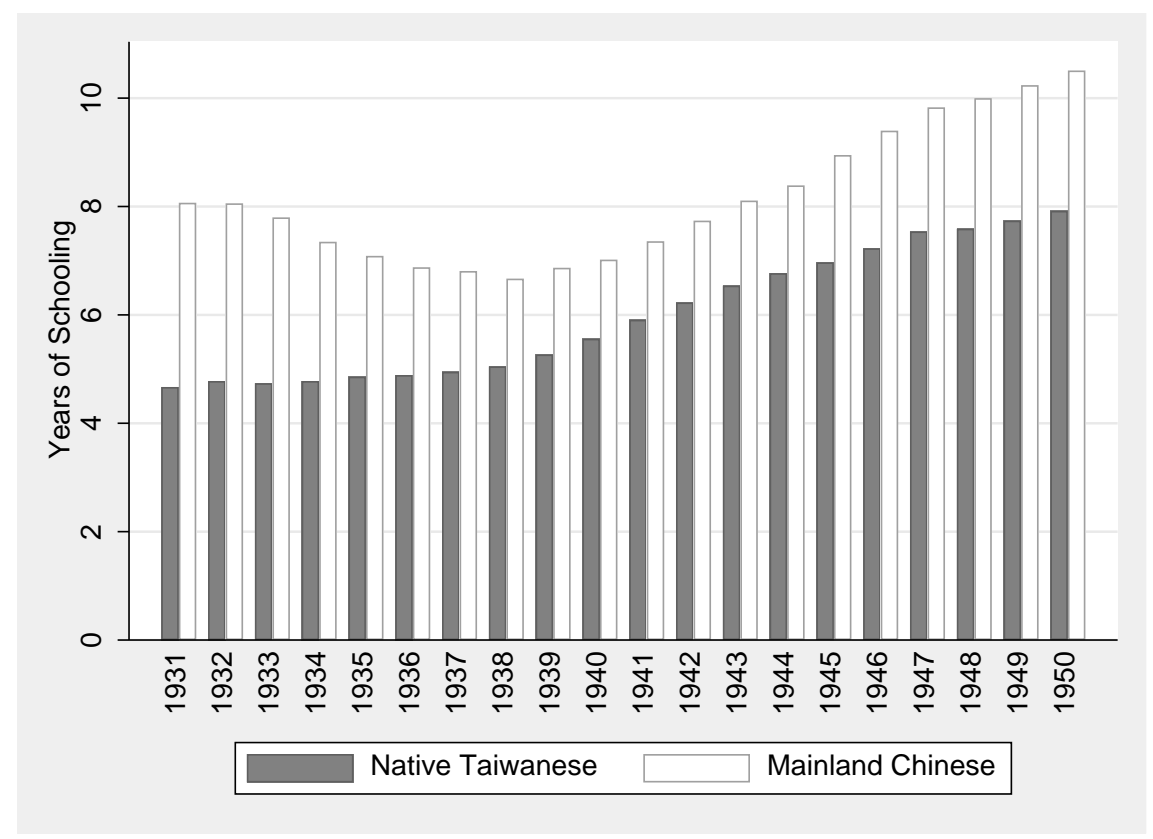

Figure A2. Schooling Years of Mainland Chinese Migrants vs. Native Taiwanese by Birth Years.

Note: Computed by the authors using the 1980 Taiwan Population Census. 
Panel A: no local characteristics
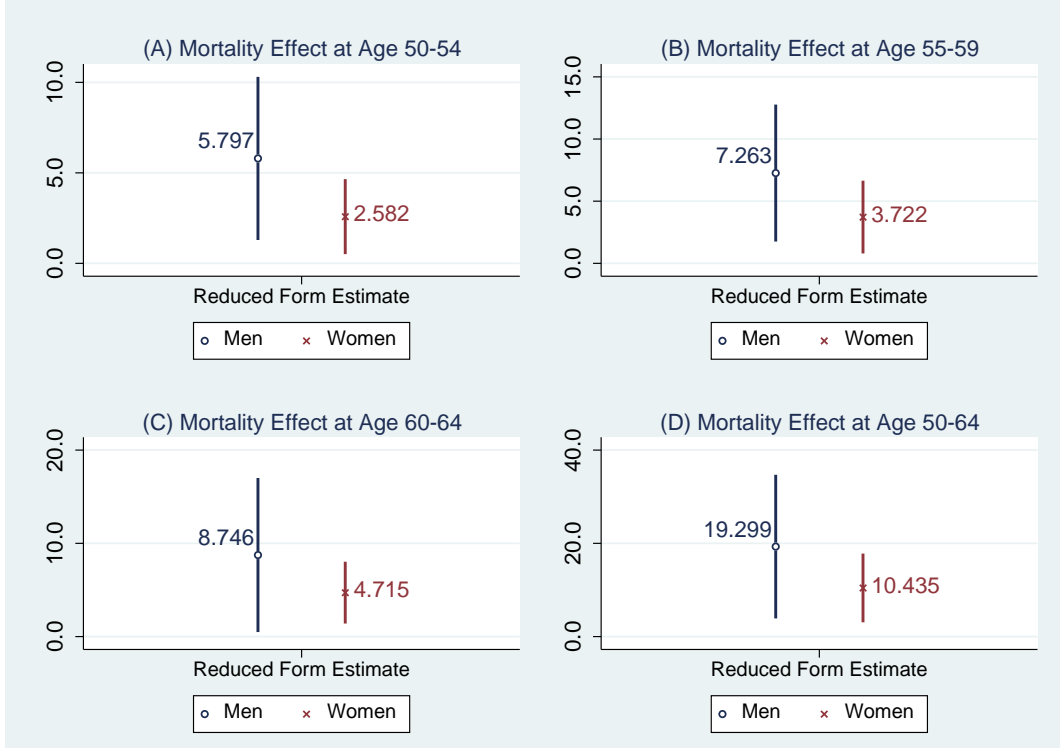

Panel B: control for local characteristics
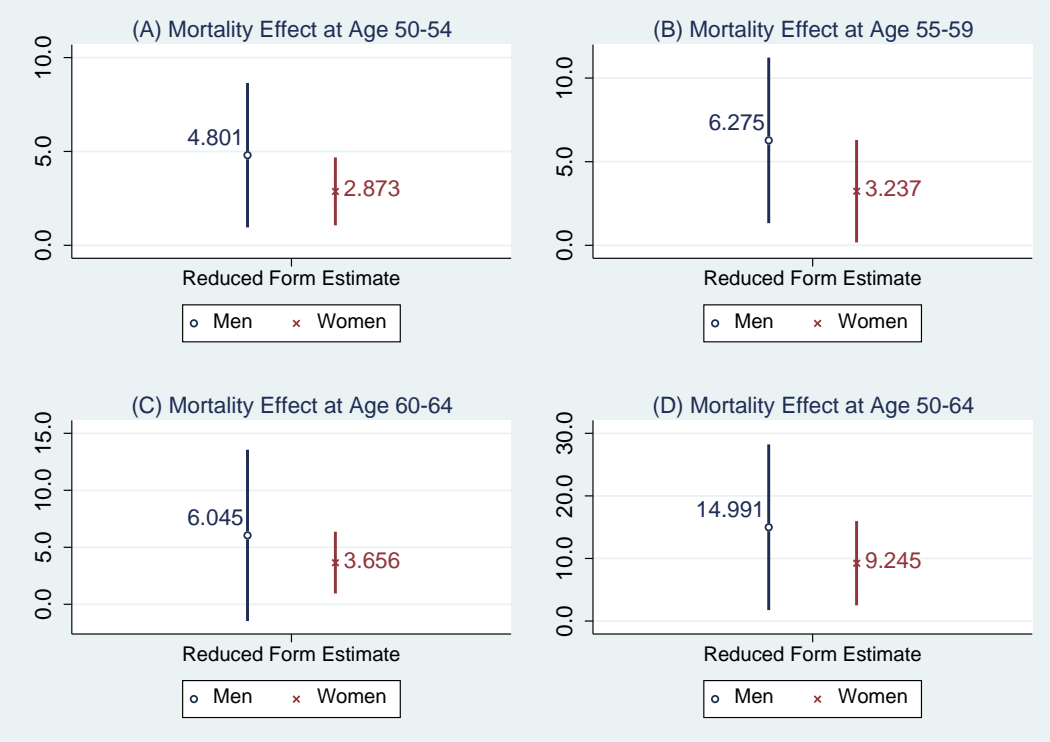

Figure A3. Reduced Form Estimates with and without Local Characteristics

Notes: All estimates are obtained from separate regressions of age-specific mortality rates on the instrumental variable controlling for the log of prime-age (20-64) men and a full set of county and birth cohort dummy variables. Estimates in Panel B further control for the local characteristics, including industry male ratio and risky job share at the county level. 